
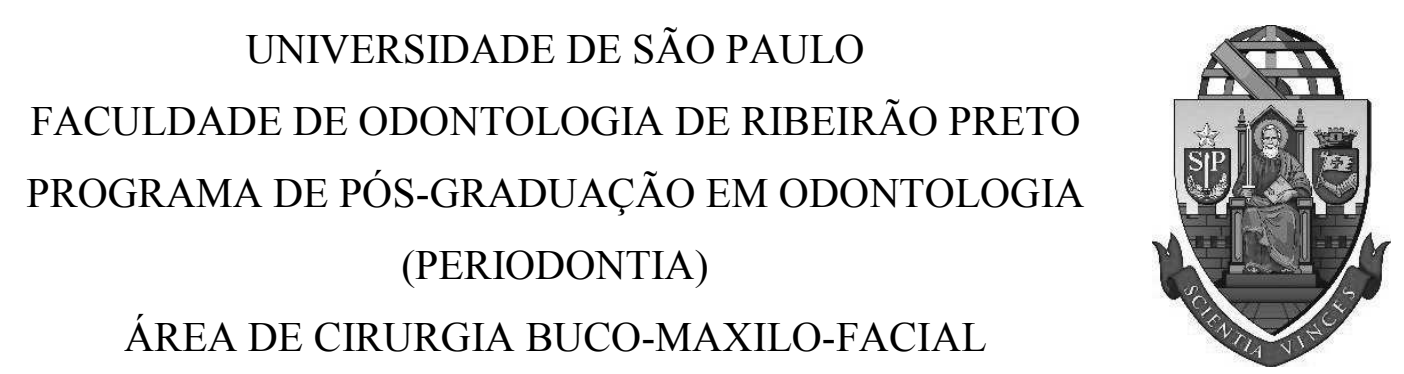

MAYSA NOGUEIRA DE BARROS MELO

Estudo laboratorial da acurácia do planejamento virtual 3D em cirurgia ortognática

Ribeirão Preto - SP

2018 
MAYSA NOGUEIRA DE BARROS MELO

Cirurgiã-Dentista

\section{Estudo laboratorial da acurácia do planejamento virtual 3D em cirurgia ortognática}

\section{Versão Corrigida}

Dissertação apresentada para obtenção do título de Mestre em Odontologia (Periodontia) da Faculdade de Odontologia de Ribeirão Preto da Universidade de São Paulo (FORP-USP).

Área de concentração: Cirurgia Buco-Maxilo-Facial

Orientador: Prof. Dr. Alexandre Elias Trivellato

Ribeirão Preto - SP 
Autorizo a reprodução e divulgação total ou parcial deste trabalho, por qualquer meio convencional ou eletrônico, para fins de estudo e pesquisa, desde que citada a fonte.

Melo, Maysa Nogueira de Barros

Estudo laboratorial da acurácia do planejamento virtual 3D em cirurgia ortognática. Ribeirão Preto, 2018.

58 p. : il. ; $30 \mathrm{~cm}$

Dissertação de Mestrado, apresentada à Faculdade de Odontologia de Ribeirão Preto/USP. Área de concentração: Cirurgia Buco-Maxilo-Facial.

Orientador: Trivellato, Alexandre Elias.

Versão Corrigida da Dissertação/Tese. A versão original se encontra disponível na Unidade que aloja o Programa.

1. Cirurgia ortognática. 2. Planejamento virtual. 3. Acurácia. 
Nome: MELO, Maysa Nogueira de Barros

Título: Estudo laboratorial da acurácia do planejamento virtual 3D em cirurgia ortognática

Dissertação apresentada à Faculdade de Odontologia de Ribeirão Preto para obtenção do título de Mestre em Odontologia (Periodontia).

Aprovado em:

Banca Examinadora

Prof. Dr.

Instituição:

Julgamento:

Prof. Dr.

Instituição:

Julgamento:

Prof. Dr.

Instituição:

Julgamento: 


\section{AGRADECIMENTOS}

Agradeço primeiramente a DEUS, pela sabedoria e por mais uma oportunidade de evolução. Ao irmão maior JESUS CRISTO e aos anjos que auxiliam a minha caminhada e me dão forças para seguir o caminho da luz. Um deles tenho certeza que é a minha avó Dona Lourdes (in memorian).

Agradeço pela família que me acolheu neste mundo, meu pai Armando e meus irmãos Leila e Arthur, à quem dedico meu amor e apoio incondicionais.

Agradeço especialmente à minha mãe Tereza e meu esposo Rafael, pois eles foram os meus maiores incentivadores. Estiveram comigo em cada dificuldade, impedindo que eu desistisse dos meus sonhos e me dando forças de forma incondicional. Aos dois, dedico este trabalho, com todo meu amor.

Agradeço também pelo amor e pela paciência daqueles que não tem tanto tempo assim para esperar pela minha companhia, mas entenderam minha ausência (meu avô Edvaldo e minha sogra Clenair).

Agradeço a todos os funcionários da FORP-USP pela atenção e carinho. Aos pacientes pela confiança, aos colegas de pós-graduação pela amizade e pelas cirurgias juntos, aos graduandos, residentes e professores pela oportunidade de aprendizado e crescimento profissional.

Agradeço ao meu orientador prof. Alexandre Elias Trivellato por todo este tempo que trabalhamos juntos. Sou grata por todo aprendizado, que não foi só acadêmico e que levarei comigo por toda minha vida profissional.

Por fim, agradeço à Fundação de Amparo à Pesquisa do Estado de São Paulo (FAPESP) pela aprovação desta linha de pesquisa (processo no 2017/11509-2) e ao Capes (Fundação de Coordenação de Aperfeiçoamento Pessoal de nível Superior) pela Bolsa do Programa de Demanda Social que tanto contribuiu para que eu pudesse concluir mais esta etapa. 


\section{RESUMO}

Os guias cirúrgicos são importantes neste caso, pois transferirão a informação do planejamento cirúrgico para o ato cirúrgico e permitirão a realização cirúrgica do movimento e as novas posições planejadas de maxila e / ou mandíbula, para corrigir a deformidade dentofacial do paciente. Assim, a preparação de guias cirúrgicos assume grande importância no sucesso do tratamento, sendo o foco deste trabalho. Foram selecionados oito pacientes previamente submetidos à cirurgia ortognática e cada paciente deu origem a um grupo, de acordo com o movimento maxilar. Grupo 1 (avanço), Grupo 2 (reposicionamento superior do incisivo - RSI), Grupo 3 (reposicionamento superior dos molares - RSM), Grupo 4 (mudança da linha média), Grupo 5 (reposicionamento inferior de incisivos - RII) Grupo 6 (reposicionamento inferior de molares - RIM), Grupo 7 (avanço com RSI e RIM) e Grupo 8 (avanço com RII e RSM) de acordo com a deformidade dentofacial do paciente. Para os Grupos de 1 a 6 planejou-se duas amplitudes de movimentação (3 e 6mm) e para os Grupos 7 e 8 apenas uma amplitude $(6 \mathrm{~mm})$. O software de planejamento virtual Dolphin Imaging $11.9^{\circledR}$ importou imagem de exame tomografia computadorizada e digitalização de arcos dentários. Foram realizadas simulações de cirurgia virtual em 3D e guias cirúrgicos virtuais foram obtidos e exportados para impressora 3D (impressão em resina). Em articulador semi-ajustável (ASA), o modelo da maxila foi separado da plataforma de montagem e o guia cirúrgico obtido do planejamento virtual 3D foi utilizado para remontar o modelo da maxila ligado ao modelo da mandíbula (posicionado de acordo com arco facial e registro pré-operatório). A maxila foi fixada na nova posição e transferida para a mesa de Erickson, na qual as medidas foram feitas para verificar o movimento planejado (direção e quantidade de movimento). Os dados foram tabulados e submetidos à análise estatística para avaliação da concordância entre o planejamento virtual 3D e os valores encontrados na Mesa de Erickson. Observou-se excelente concordância entre os métodos, independentemente da direção, ponto de referência analisado ou quantidade da movimentação (3 ou 6mm). A maior variação encontrada foi de $0,42 \mathrm{~mm}$ na amplitude de movimentação de $6 \mathrm{~mm}$ e a maior média $(0,07 \mathrm{~mm})$ na região do elemento 16 , evidenciando a alta concordância entre os métodos de obtenção de guias cirúrgicos para cirurgia ortognática. Não foram encontradas diferenças estatisticamente significantes, e portanto, a obtenção de guias cirúrgicos por meio do planejamento virtual 3D em cirurgia ortognática possui excelente concordância com a tradicional Mesa de Erickson (Cirurgia de Modelos).

Palavras-chave: Cirurgia ortognática. Planejamento virtual. Acurácia. 


\section{ABSTRACT}

Surgical guides are important in this case, since they will transfer the information of surgical planning to the surgical act and allow the surgical achievement of the movement and the new planned positions of maxilla and / or mandible, to correct the patient's dentofacial deformity. Thus, preparation of surgical guides assumes great importance on treatment success, being the focus of this work. It was selected eight patients previously submitted to Orthognathic Surgery and each patient gave rise to a group, according to the maxillary movement. Group 1 (advancement), Group 2 (upper repositioning of incisor - URI), Group 3 (upper repositioning of molars - URM), Group 4 (midline changing), Group 5 (down repositioning of incisors - DRI) Group 6 (down repositioning of molars - DRM), Group 7 (advancement with URI and DRM) and Group 8 (advancement with DRI and URM) according to the patient's dentofacial deformity. To Groups 1 to 6 two amplitudes of movement were planned ( 3 and $6 \mathrm{~mm}$ ) and for Groups 7 and 8 only one amplitude $(6 \mathrm{~mm})$. Dolphin Imaging $11.9^{\circledR}$ virtual planning software imported image of computed tomographic examination and scanning of dental arches. Simulation of 3D virtual surgery was performed and virtual surgical guides obtained, which were exported to the $3 \mathrm{D}$ printer (resin impression). In semi-adjustable articulator (SAA) the maxilla model was separated from the SAA mounting platform and the surgical guide obtained from 3D virtual surgical planning was used to reassemble the maxilla model linked to mandible model (positioned according to facial bow and preoperative registration). The maxilla was fixed in the new position and transferred to Erickson's table, in which measurements were made to verify the planned movement (direction and amount of movement). The data were tabulated and submitted to statistical analysis to evaluate the agreement between $3 \mathrm{D}$ virtual planning and the values found in Erickson's Table. There was an excellent agreement between the methods, regardless of direction, reference point analyzed or amount of movement ( 3 or $6 \mathrm{~mm}$ ). The greatest variation was $0.42 \mathrm{~mm}$ in the movement amplitude of $6 \mathrm{~mm}$ and the highest mean $(0,07 \mathrm{~mm})$ in the region of element 16 , evidencing the high agreement between the methods of attainment of surgical guides for orthognathic surgery. No statistical significant differences were found, and so, the attainment of surgical guides for orthognathic surgery by 3D virtual surgical planning in orthognathic surgery has an excellent agreement with the traditional Erickson's table (Model Surgery).

Keywords: Orthognathic surgery. Virtual planning. Accuracy. 


\section{LISTA DE TABELAS}

Tabela 1 - Movimentações maxilares avaliadas no estudo

Tabela 2 - Etapas do estudo

Tabela 3 - Diagnóstico pré-operatório

Tabela 4 - Resultados Grupo 1 - AVANÇO (3mm)

Tabela 5 - Resultados Grupo 1 - AVANÇO (6mm)

Tabela 6 - Resultados Grupo 2 - REPOSICIONAMENTO SUPERIOR

INCISIVOS (3mm)

Tabela 7 - Resultados Grupo 2 - REPOSICIONAMENTO SUPERIOR INCISIVOS $(6 \mathrm{~mm})$

Tabela 8 - Resultados Grupo 3 - REPOSICIONAMENTO SUPERIOR 33 MOLARES (3mm)

Tabela 9 - Resultados Grupo 3 - REPOSICIONAMENTO SUPERIOR 34 MOLARES (6mm)

Tabela 10 - Resultados Grupo 4 - LINHA MÉDIA (3mm)

Tabela 11 - Resultados Grupo 4 - LINHA MÉDIA (6mm)

Tabela 12 - Resultados Grupo 5 - REPOSICIONAMENTO INFERIOR 37 INCISIVOS $(3 \mathrm{~mm})$ 
Tabela 13 - Resultados Grupo 5 - REPOSICIONAMENTO INFERIOR INCISIVOS $(6 \mathrm{~mm})$

Tabela 14 - Resultados Grupo 6 - REPOSICIONAMENTO INFERIOR MOLARES (3mm)

Tabela 15 - Resultados Grupo 6 - REPOSICIONAMENTO INFERIOR MOLARES (6mm)

Tabela 16 - Resultados Grupo 7 - AVANÇO + RS INCISIVOS + RI MOLARES

Tabela 17 - Resultados Grupo 8 - AVANÇO + RI INCISIVOS + RS MOLARES

Tabela 18 - Análise descritiva dos dados.

Tabela 19 - Análise descritiva da variação entre Dolphin Imaging $11.9^{\circledR} \mathrm{e}$ Mesa de Erickson.

Tabela 20 - Comparações do delta (Dolphin - Mesa de Erickson) entre os movimentos ( 3 e $6 \mathrm{~mm}$ ) em cada ponto de referência

Tabela 21 - Coeficiente de correlação intraclasses de acordo com o ponto de referência e a quantidade de movimentação.

Tabela 22 - Coeficiente de correlação intraclasses de acordo com o ponto de referência 


\section{LISTA DE FIGURAS}

Figura 1 - Medidas tridimensionais dos modelos laboratoriais (préoperatório)

Figura 2 - Medida da dimensão vertical pré-operatória

Figura 3 - Medida da dimensão vertical após interposição do guia cirúrgico

Figura 4 - Medidas tridimensionais dos modelos laboratoriais (após posicionamento do guia cirúrgico)

Figura 5 - Gráfico de Bland-Altman avaliando a variação da diferença entre as medidas do Dolphin Imaging $11.9^{\circledR}$ e Mesa de Erickson na Linha Média Superior (LMS).

Figura 6 - Gráfico de Bland-Altman avaliando a variação da diferença entre as medidas do Dolphin Imaging $11.9^{\circledR}$ e Mesa de Erickson no elemento 16 .

Figura 7 - Gráfico de Bland-Altman avaliando a variação da diferença entre as medidas do Dolphin Imaging $11.9^{\circledR}$ e Mesa de Erickson no elemento 26.

Figura 8 - Gráfico de Dispersão avaliando a concordância entre as medidas do Dolphin Imaging $11.9^{\circledR}$ e Mesa de Erickson na Linha Média Superior (LMS).

Figura 9 - Gráfico de Dispersão avaliando a concordância entre as medidas do Dolphin Imaging $11.9^{\circledR}$ e Mesa de Erickson no elemento 16.

Figura 10 - Gráfico de Dispersão avaliando a concordância entre as medidas do Dolphin Imaging $11.9^{\circledR}$ e Mesa de Erickson no elemento 26. 


\section{SUMÁRIO}

1. INTRODUÇÃO 11

2. REVISÃO DE LITERATURA 14

3. PROPOSIÇÃO 18

4. METODOLOGIA 19

4.1 Aspectos éticos da pesquisa 19

4.2 Local da pesquisa 19

4.3 Critérios de inclusão e não inclusão na seleção dos pacientes 19

$\begin{array}{ll}4.4 \text { Paradigma } & 20\end{array}$

$\begin{array}{ll}4.5 \text { Materiais utilizados } & 20\end{array}$

$\begin{array}{ll}\text { 4.6 Descrição detalhada da Metodologia } 20 & 20\end{array}$

$\begin{array}{ll}4.7 \text { Análise estatística } & 21\end{array}$

4.8 Metodologia para aquisição da imagem 27

5. RESULTADOS 28

6. DISCUSSÃO 51

7. CONCLUSÃO 55

8. REFERÊNCIAS 56 


\section{INTRODUÇÃO}

O planejamento cirúrgico virtual é uma ferramenta que pode ser utilizada em toda a área de Cirurgia e Traumatologia Buco-Maxilo-Faciais, incluindo o planejamento e instalação de implantes dentários, reconstrução da articulação temporomandibular, tratamento de traumatismos panfaciais e tumores da região Buco-Maxilo-Facial. (1)

Avanços no uso de "softwares" para planejar cirurgia ortognática tridimensionalmente (incorporando dados de tomografias computadorizadas multislice ou de feixe cônico) tornaramse valiosas ferramentas para o diagnóstico, planejamento do tratamento e avalição pósoperatória. Para tanto, necessita-se de precisão. (2)

Classicamente, o planejamento em cirurgia ortognática é realizado por meio da montagem de modelos de gesso em articulador semi-ajustável e posterior confecção manual de guias cirúrgicos em resina acrílica.(2-4) Limitações deste método são o tempo necessário para este tipo de planejamento e a complexidade de etapas do mesmo.(3) Erros cirúrgicos podem ser introduzidos em cada etapa deste processo. (5)

Tais limitações e o desenvolvimento da Tomografia Computadorizada de Feixe Cônico (TCFC) permitiram o uso de "softwares" e sistemas de navegação, com técnicas de prototipagem rápida para obtenção de guias cirúrgicos em cirurgia ortognática, resultando em maior precisão da transferência do planejamento cirúrgico.(2) A TCFC permite ainda o acompanhamento pós-operatório das mudanças executadas por meio de medidas precisas de distâncias e ângulos, com imagens precisas das estruturas ósseas e baixa exposição à radiação.

O planejamento virtual também pode ser associado a guias cirúrgicos para osteotomia (também chamados de “templates"), que permitem o planejamento e acurácia no reposicionamento dos segmentos ósseos em Cirurgia Ortognática bimaxilar.(3) Posicionar a maxila corretamente é a chave para a cirurgia ortognática, pois a maxila está localizada no centro da face e guia todos os movimentos dos ossos faciais. O método mais adequado para otimizar este controle intraoperatório é controverso. (5)

As diferentes maneiras de transferência do planejamento virtual para o ato cirúrgico podem influenciar na acurácia dos resultados e por isso, é necessário investigar as vantagens e desvantagens dos diferentes métodos de aferição intraoperatória (medição de pontos de referência esqueléticos). (3) Com o objetivo de verificar as movimentações realizadas ainda durante o transcirúrgico, tem sido utilizada a navegação intraoperatória, também chamada de cirurgia guiada. Esta permite ao cirurgião localizar precisamente os instrumentos cirúrgicos e 
pontos de referência anatômicos em tempo real. Em conjunto com os avanços no planejamento cirúrgico virtual pré-operatório tornou-se uma ferramenta poderosa e pode ser uma alternativa aos "templates" para osteotomia. (7)

O planejamento virtual permite bons resultados, porém ainda é limitado pela experiência do cirurgião. Maiores avanços na aquisição das imagens de tomografia de feixe cônico, assim como na predição do posicionamento dos tecidos moles por meio do escaneamento de superfície 3D a laser e a criação de uma plataforma virtual de comunicação trariam um novo paradigma para o planejamento em cirurgia ortognática. (2)

Tem ocorrido uma mudança na filosofia convencional - apenas centrada na oclusão para um planejamento também baseado nos tecidos moles, com o objetivo de atingir perfis faciais mais harmoniosos. Muitas análises cefalométricas bidimensionais tem sido utilizadas para quantificar o perfil dos tecidos moles faciais, porém estas são consideradas limitadas para avaliar uma face tridimensional. A fotogrametria, nesse contexto, aparece como um método seguro e não-invasivo para obtenção de imagens tridimensionais. Trata-se da obtenção de fotografias tridimensionais de alta qualidade, possibilitando avaliar e quantificar os resultados obtidos nos tecidos moles dos pacientes comparando pré-operatório, o planejamento e o pósoperatório. (8)

A predição das mudanças nos tecidos moles que acompanham os movimentos planejados nos tecidos duros é a chave da simulação cirúrgica. Esta simulação tridimensional acurada é essencial no planejamento e escolha do tratamento, aumentando sua complexidade. (9) Predições algorítmicas combinadas à TCFC de maneira geral são precisas para simulação das mudanças de tecidos moles após o avanço mandibular. (10) Do ponto de vista teórico, há um aumento na complexidade ainda mais desafiador em cirurgias bimaxilares. $(9,10)$

Os avanços já ocorridos promoveram um impacto significante também na especialidade de Cirurgia e Traumatologia Buco-Maxilo-Faciais e nas suas instituições formadoras. É cada vez maior a busca por otimizar tempo sem perder qualidade. Por meio do planejamento virtual existe um ganho de tempo de cerca de 30,1\% a menos em casos mais simples (cirurgias monomaxilares), 29\% para casos complexos (cirurgias bimaxilares) e 26,3\% para casos envolvendo segmentações. (11) Este é o maior argumento para a implementação do planejamento virtual em cursos de Cirurgia e Traumatologia Buco-Maxilo-Faciais. O uso de planejamento virtual e aquisição de guias cirúrgicos $3 \mathrm{D}$ resulta em economia de tempo do cirurgião e ajuda na melhor adequação da carga horária de residentes. (11) 
O planejamento por meio de cirurgia de modelos convencional é laborioso, demanda tempo e pode potencialmente conter erros. (11) Erickson em 1989, descreveu a técnica de Plataforma de Modelos, utilizando paquímetros para a aferição e melhor controle das movimentações realizadas na cirurgia de modelos convencional. A Plataforma de Modelos é um instrumento desenhado para medição precisa, de maneira reprodutível, dos modelos montados em articulador nos três planos espaciais. Usando um plano comum de referência, os modelos são precisamente correlacionados com a radiografia cefalométrica e o exame clínico.

Por outro lado, apesar de mais preciso, o planejamento virtual (PV) necessita de maior atenção para adequada intercuspidação entre as arcadas, que ainda é considerada difícil e subjetiva. (13) A imprecisão da visualização do relacionamento interoclusal no planejamento virtual em cirurgia ortognática realizado por meio da TCFC é um importante desafio para os cirurgiões. (14) Não é possível obter uma imagem tridimensional precisa da oclusão dentária quando capturada de "boca fechada", além dos artefatos de metal presentes. (15) Além disso, durante a TCFC o paciente é usualmente posicionado com os dentes na Máxima Intercuspidação Habitual (MIH), e não em Relação Cêntrica (RC) - posição utilizada para o PV. (16) As maiores variações são encontradas no posicionamento do eixo $y$. (14)

Muitos autores propuseram a realização de mais de uma tomada tomográfica para maior fidedignidade dos detalhes anatômicos da oclusão do paciente, porém atualmente a solução mais inócua e barata é a utilização dos scanners, que permitem a riqueza de detalhes necessária e evitam que o paciente seja exposto a mais radiação. (14) Por meio dos scanners intra-orais é possível obter informações detalhadas a respeito da oclusão dentária, com a mandíbula posicionada em relação cêntrica. (15)

O presente trabalho teve portanto, o objetivo de verificar laboratorialmente a acurácia do planejamento virtual 3D em cirurgia ortognática para a obtenção de guias cirúrgicos, comparando o mesmo à Mesa de Erickson. 


\section{REVISÃO DE LITERATURA}

Muitos trabalhos sobre as vantagens e acurácia do planejamento virtual são encontrados na literatura, porém com número limitado de pacientes e metodologias diferentes de apresentação de dados, o que dificulta a realização de meta-análises. (3)

Centenero \& Hernández-Alfaro em 2012 realizaram um estudo para determinar as vantagens do planejamento virtual 3D em cirurgia ortognática por meio do programa Simplant OMS $10.1^{\circledR}$. Teve como amostra 16 pacientes e os mesmos foram submetidos ao planejamento convencional com obtenção de guias cirúrgicos em resina acrílica e também realizou-se a impressão de guias cirúrgicos oriundos do planejamento virtual 3D. Os guias cirúrgicos convencionais foram classificados como grupo controle. Na sala cirúrgica, considerada um cenário autêntico para comparação segundo os autores, os guias cirúrgicos foram comparados por meio de medidas clínicas. Um alto coeficiente de correlação foi obtido em 15 dos 16 casos. Os autores concluíram que o planejamento cirúrgico virtual 3D é confiável para o planejamento e impressão de guias cirúrgicos em cirurgia ortognática.(17)

Já Hernández-Alfaro \& Guijarro-Martínez em 2013 buscaram um método inovador para avaliar a acurácia do planejamento virtual em cirurgia ortognática e a fabricação dos guias cirúrgicos. Foi realizada uma avaliação in vitro de três modelos de crânio dentados seguida de avaliação in vivo de seis pacientes consecutivos. Foi realizado o scaneamento intra-oral no préoperatório, trans e pós-operatório. Os autores compararam o posicionamento dos maxilares no planejamento virtual com o obtido no trans e pós-operatório (por meio de escaneamento) e encontraram alta acurácia. As maiores variações encontradas ocorreram no eixo $y$. Relataram também, que uma importante vantagem do PV é a possibilidade de testar inúmeros planos de tratamento, diferentemente da tradicional cirurgia de modelos. (14)

Em estudo publicado por Herford, Stringer \& Tendon em 2014, os autores demonstram a progressão dos avanços tecnológicos e sua contribuição para o desenvolvimento da cirurgia craniofacial. Afirmam que o advento do planejamento cirúrgico virtual tem permitido melhores métodos para o planejamento cirúrgico, disponibilizando aos pacientes o melhor resultado possível. Além disso, ressaltam que os guias cirúrgicos adquiridos por meio de programa de computador minimizam e em alguns casos até eliminam a possibilidade de erro humano inerente à cirurgia de modelos tradicional. (18) Outra vantagem citada no trabalho é que a tomografia computadorizada permite a cirurgiões e ortodontistas a possibilidade de avaliação do tecido ósseo do paciente sem a sobreposição dos tegumentos, o que não era possível com as técnicas tradicionais bidimensionais. (18) Adicionalmente, o PV também tornou mais eficiente 
o tratamento de pacientes que necessitam de cirurgia ortognática, especialmente aqueles com assimetrias faciais significantes. (18)

Swennen em 2014 por meio de estudo prospectivo avaliou 350 casos consecutivos de cirurgia ortognática conduzidos por um único cirurgião. Ressaltou a necessidade de padronização das etapas do PV para maior segurança nos resultados e menor ocorrência de erros. (19) Apresentou em seu trabalho as etapas para um planejamento virtual adequado e elucidou ainda que a precisão e os resultados estão intimamente ligados à experiência clínica de cada cirurgião e por isso, há a necessidade de estabelecimento de uma sequência de etapas para o PV. (19)

Stokbro, Aagaard, Torkov et. al. 2014 realizaram uma revisão sistemática para analisar a precisão e acurácia do PV para procedimentos ortognáticos comparando os resultados cirúrgicos atuais da cirurgia ortognática relatados em casos clínicos. Uma pesquisa sistemática na literatura foi conduzida para identificar relatos de caso com mais de 5 pacientes comparando o PV com o resultado obtido. Inúmeras publicações na literatura tratam do PV, porém a maioria delas enfatiza o planejamento por meio de casos clínicos. Foram encontrados 428 artigos e apenas 7 foram incluídos. O critério de sucesso estabelecido foi a existência de discrepâncias de até $2 \mathrm{~mm}$, para seis dos artigos incluídos. Os autores concluíram que o PV é um método preciso e reprodutível para o planejamento em cirurgia ortognática. Por outro lado, não foi possível realizar uma meta-análise pela ausência de padronização da apresentação dos dados nas publicações. (20) Maiores estudos na área ainda são necessários para efetivamente validar a precisão do planejamento virtual. (20)

Hemelen, Genechten, Renier et. al. 2015 realizaram um estudo prospectivo duplo-cego randomizado com 66 pacientes para comparar a acurácia da predicção do planejamento tradicional 2D com o PV. A acurácia das predicções do tecido ósseo e o perfil dos tecidos moles foram investigados. O PV apresentou maior acurácia na predicção dos tecidos moles isoladamente, porém não foram encontradas diferenças estatisticamente significantes entre os métodos quando comparados os resultados para o tecido ósseo. Os autores enfatizaram também que o sucesso está intimamente relacionado ao cuidado e da reprodutibilidade do planejamento na sala de cirurgia. E além disso, afirmaram que a cirurgia ortognática não permite somente ganhos na estética, fala, mastigação e deglutição, mas também um completo ganho de qualidade de vida oferecido ao paciente. (21)

Hatamleh, Turner, Bhamrah et. al. em 2016 publicaram um relato de caso do tratamento de deformidade dentofacial classe III por meio de cirurgia ortognática. Para o caso relatado, os 
autores realizaram o planejamento virtual e o convencional (por meio de articulador semiajustável). Afirmaram que o planejamento virtual já é considerado seguro, útil, reprodutível, eficiente e também uma alternativa de baixo custo. Como vantagens adicionais, concluíram que há maior acurácia, melhores resultados e redução do tempo laboratorial. Uma outra desvantagem do planejamento convencional citada é que os guias cirúrgicos convencionais deformam mais facilmente, dificultando seu ajuste. (13)

Borba, Haupt, Romualdo et. al. 2016 realizaram um estudo retrospectivo de casos de cirurgia ortognática para avaliar a variabilidade entre o planejamento e os movimentos obtidos. Utilizaram pontos de referência cefalométricos da análise cefalométrica tridimensional de MacNamara em tomografias computadorizadas. Após avaliação dos resultados dos 50 pacientes incluídos na amostra, foram encontradas diferenças entre pré e pós-operatório de $2.0 \pm 2.0 \mathrm{~mm}$ nos pontos de referêcia maxilares. O gênero e o tipo de deformidade não demonstraram influência estatisticamente significante na acurácia dos movimentos cirúrgicos. Concluiu-se no estudo que a variabilidade dos resultados teve valores clinicamente aceitáveis e que o PV é uma ferramenta viável com alto nível de acurácia e precisão. Além disso, o estudo ressaltou duas importantes vantagens do planejamento virtual: a possibilidade de realizar o acompanhamento pós-operatório dos resultados obtidos comparando-os ao planejamento e os ganhos obtidos em experiência para o cirurgião em tratamentos futuros. (22)

Resnick, Inverso, Wrzosek et. al. 2016 realizaram um estudo para comparar os custos necessários entre o PV e o planejamento convencional. A amostra incluiu 43 pacientes divididos em três grupos (simétricos submetidos a cirurgias sem segmentação, assimétricos e pacientes submetidos a cirurgias com segmentação). No estudo, os autores afirmam que o PV e a impressão de guias cirúrgicos tridimensionais estão se tornando padrão para cirurgia ortognática bimaxilar, e seu menor custo e tempo laboratorial são estatisticamente significantes, tanto para casos mais simples como para pacientes assimétricos ou cirurgias com segmentações. (23) Ressaltam que maiores estudos são necessários para avaliar também as cirurgias monomaxilares, assim como a diferença de tempo em sala de centro cirúrgico dos dois tipos de planejamento. (23)

Já De Riu et. al. 20017 buscaram avaliar a diferença entre o planejamento virtual 3D e o posicionamento pós-operatório dos maxilares de 49 pacientes submetidos a cirurgia ortognática. Os autores analisaram cefalometrias frontal e lateral utilizando um programa de computador para planejamento virtual 3D. Doze dos quinze parâmetros avaliados não apresentaram diferenças estatisticamente significantes. Somente as grandezas cefalométricas 
SNA, SNB e a altura facial inferior (AFAI) demonstraram diferenças estatisticamente significantes, especialmente nos casos que envolveram mentoplastias. Os autores concluíram que ocorreu um bom nível de precisão para os parâmetros avaliados, e foi detectada uma tendência de projeção dos maxilares abaixo do esperado, provavelmente em virtude de posicionamento condilar incorreto durante o procedimento cirúrgico.(24)

Chin et. al. 2017 também buscaram avaliar a acurácia do planejamento cirúrgico virtual por meio de um método tridimensional de análise. Dez pacientes foram avaliados e comparouse as medidas obtidas no planejamento com os resultados pós-operatórios. Nenhuma diferença estatisticamente significante foi encontrada entre o planejamento e o resultado pós-operatório. Os autores concluíram que o planejamento cirúrgico virtual 3D foi transferido com sucesso por meio dos guias cirúrgicos fabricados com o auxílio do programa Dolphin Imaging $11.8^{\circledR}$. Concluíram também que estes guias oferecem resultado cirúrgico preciso em cirurgia ortognática.(25)

Nos anos de 1960, os cirurgiões raramente dependiam do tratamento ortodôntico para movimentação dentária antes da cirurgia ortognática. Este passo tornou-se importante posteriormente pela maior estabilidade dos resultados e satisfação pós-operatória dos pacientes com os resultados. Recentemente, a cirurgia ortognática com benefício antecipado tem sido muito estudada. Para avaliação da acurácia do planejamento virtual em cirurgia ortognática com benefício antecipado, Tran et. al. 2018 selecionaram quinze pacientes portadores de deformidade dentofacial Classe III. Os autores compararam as medidas obtidas no planejamento virtual com os resultados pós-operatórios. Concluíram que o planejamento cirúrgico virtual e a impressão $3 \mathrm{D}$ dos guias cirúrgicos facilitaram o diagnóstico e o planejamento do tratamento, oferecendo resultados precisos para cirurgia ortognática com benefício antecipado.(26)

O presente trabalho realizará um estudo comparativo entre o planejamento virtual 3D e a Mesa de Erickson em cirurgia ortognática. 


\section{PROPOSIÇÃO}

Realizar um estudo laboratorial em cirurgia ortognática por meio da comparação entre o planejamento tradicional (Mesa de Erickson - Cirurgia de Modelos) e o planejamento cirúrgico virtual 3D (programa Dolphin Imaging $11.9^{\circledR}$ ). 


\section{METODOLOGIA}

\subsection{Aspectos éticos da pesquisa}

Este estudo foi encaminhado ao Comitê de Ética e Pesquisa da Faculdade de Odontologia de Ribeirão Preto - USP para apreciação e aprovação, seguindo as Diretrizes e Normas Regulamentadoras, de acordo com Resolução (CNS 466/12). Aprovação CAAE no 69600417.2 .0000 .5419 .

\subsection{Local da pesquisa}

O desenvolvimento do estudo deu-se na Faculdade de Odontologia de Ribeirão Preto da Universidade de São Paulo (FORP-USP).

\subsection{Critérios de inclusão e não inclusão na seleção dos pacientes}

Foram selecionados 08 prontuários de pacientes já assistidos pelo Departamento de Cirurgia e Traumatologia Buco-Maxilo-Facial e Periodontia da Faculdade de Odontologia de Ribeirão Preto - USP de maneira aleatória simples.

Como critérios de inclusão, foram selecionados:

1. Prontuários de pacientes portadores de deformidade dentofacial que foram submetidos à cirurgia ortognática, totalmente preenchidos;

2. Disponibilidade do exame de imagem requerido: tomografia computadorizada de feixe cônico da face pré-operatória;

3. Disponibilidade de escaneamento de arcos dentários;

4. Disponibilidade dos modelos de gesso montados em articulador semi-ajustável e não operados.

Como critérios de não inclusão, foram considerados os seguintes parâmetros:

1. Prontuário com preenchimento incompleto;

2. Ausência do exame de imagem requerido: tomografia computadorizada de feixe cônico da face e pré-operatória;

3. Indisponibilidade do escaneamento dos arcos dentários;

4. Indisponibilidade dos modelos de gesso montados em articulador semiajustável e não operados. 


\subsection{Paradigma}

O trabalho foi desenvolvido dentro do paradigma tradicional qualitativo, quantitativo, retrospectivo, descritivo e analítico.

\subsection{Materiais utilizados}

- Articulador semi-ajustável.

- $\quad$ Programa de computador Dolphin Imaging $11.9^{\circledR}$.

- Scanner intra-oral.

- Mesa de Erickson.

- Impressora $3 \mathrm{D}$ e resina atóxica resistente à temperatura $\left(\approx 180^{\circ} \mathrm{C}\right)$.

- Cera utilidade.

- Serra para modelos.

- Massa de modelar.

- Lâmina de Bisturi n ${ }^{\circ} 11$.

- Compasso de ponta seca.

\subsection{Descrição detalhada da metodologia}

Este trabalho buscou avaliar tridimensionalmente o posicionamento da maxila conseguido por meio do planejamento virtual, verificando o movimento obtido na Mesa de Erickson.

Foram selecionados 08 prontuários de pacientes previamente submetidos à Cirurgia Ortognática dos maxilares de acordo com os critérios de inclusão e exclusão. Cada paciente deu origem a um grupo, de acordo com o movimento maxilar. Foi utilizada a Tomografia Computadorizada de Feixe Cônico de face do paciente selecionado, que é um dos exames préoperatórios solicitados rotineiramente.

Foi utilizada também a montagem em articulador semi-ajustável, com modelos de gesso em posição pré-operatória (para confecção dos modelos laboratoriais de simulação).

Todos os passos foram realizados pelo mesmo operador, que utilizou o programa de computador Dolphin Imaging $11.9^{\circledR}$ para as simulações das movimentações maxilares e o 
escaneamento dos arcos dentários. A impressão dos guias cirúrgicos virtuais foi realizada na mesma impressora 3D em resina.

Primeiramente, os modelos laboratoriais montados em articulador semi-ajustável foram medidos tridimensionalmente na Mesa de Erickson por meio de pontos de referência anatômicos para a posterior comparação das medidas obtidas (foram realizadas três medições para cada ponto):

- Linha Média Superior (LMS);

- Pontas das cúspides mésio-vestibulares dos elementos 16 e 26;

- Tais medidas foram realizadas tridimensionalmente (ver Figura 1 na página a seguir).

\subsection{Análise Estatística}

Os dados obtidos foram tabulados e submetidos à análise estatística. Para as comparações do delta (Dolphin Imaging $11.9^{\circledR}$ - Mesa de Erickson) entre os movimentos (3mm e $6 \mathrm{~mm}$ ) em cada local foi proposto o modelo de regressão linear com efeitos mistos (efeitos aleatórios e fixos). Os modelos lineares de efeitos mistos são utilizados na análise de dados em que as respostas estão agrupadas (mais de uma medida para um mesmo indivíduo) e a suposição de independência entre as observações num mesmo grupo não é adequada (27). Os pressupostos de normalidade e homocedasticidade dos resíduos foram verificados. Para as comparações foi utilizado o pós-teste por contrastes ortogonais.

Para todas as comparações adotou-se um nível de significância de 5\%. As concordâncias entre os métodos foram analisadas através do cálculo do CCI (Coeficiente de correlação intraclasse) para medidas repetidas, usando os componentes de variância de um modelo linear de efeitos mistos (utilizando o pacote cccrm do software R) (28).

Para melhor visualização da concordância, as medidas foram representadas pelos gráficos de dispersão e pelos gráficos de Bland-Altman, onde o eixo das ordenadas recebe os valores da diferença de medidas de cada indivíduo e o eixo das abscissas representa a média entre as duas medidas (29). Todos os gráficos apresentados foram feitos com o auxílio do Medcalc versão 12.5 e as análises através do software R, versão 3.4.1 (30). 


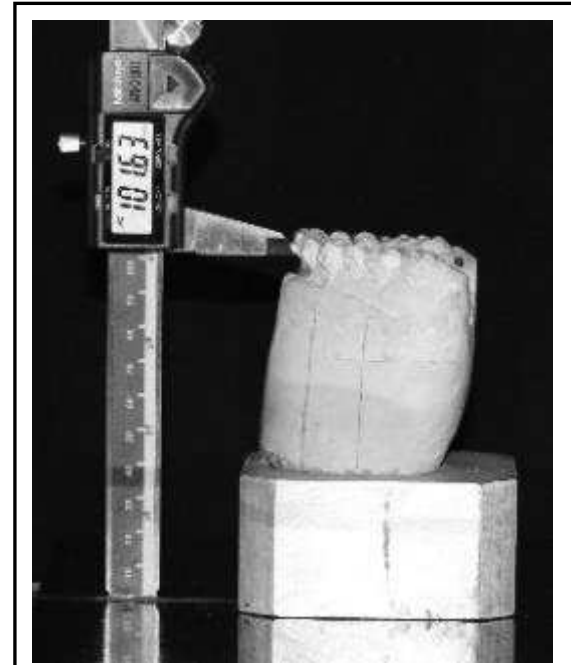

(A1)

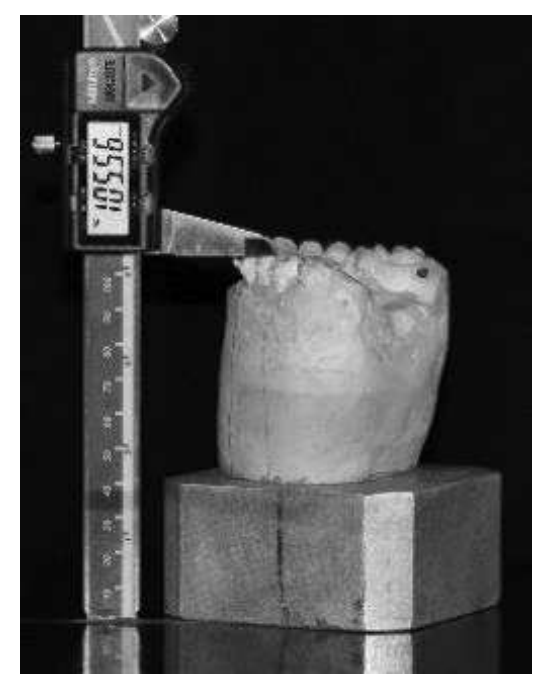

(A2)

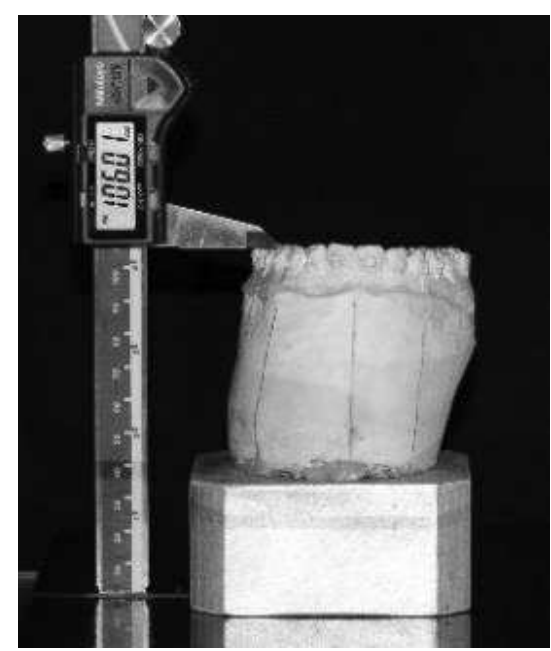

(A3)

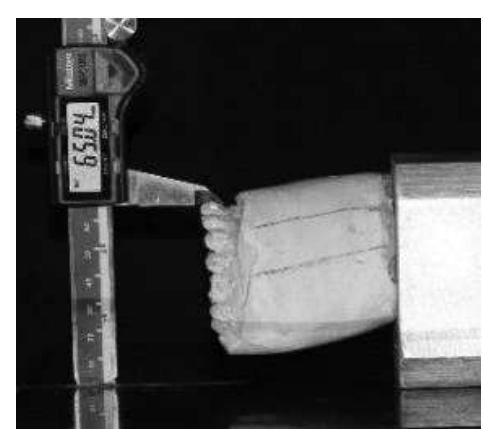

(B1)

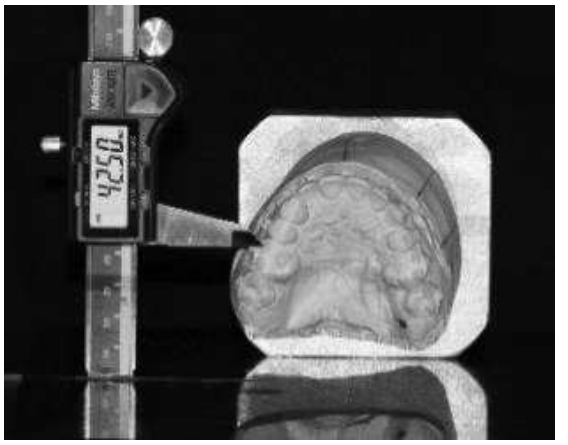

(B2)

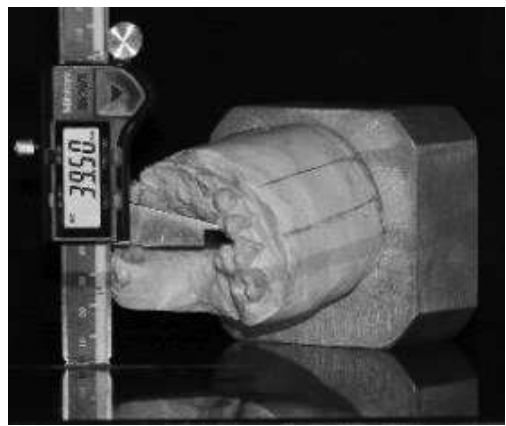

(B3)

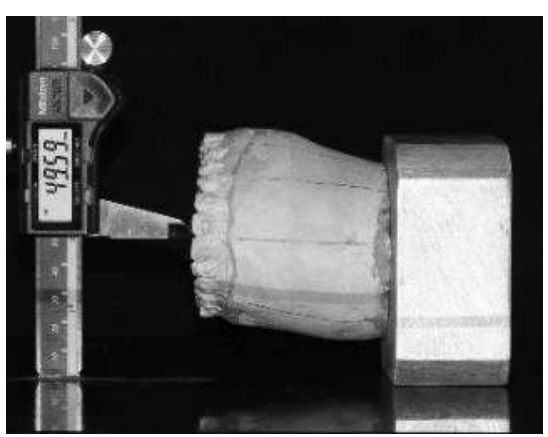

(C1)

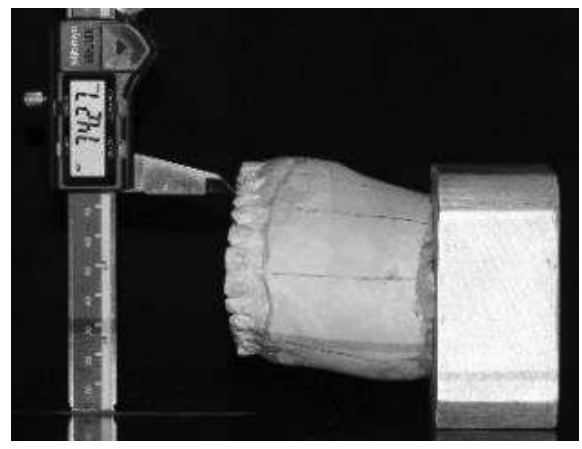

(C2)

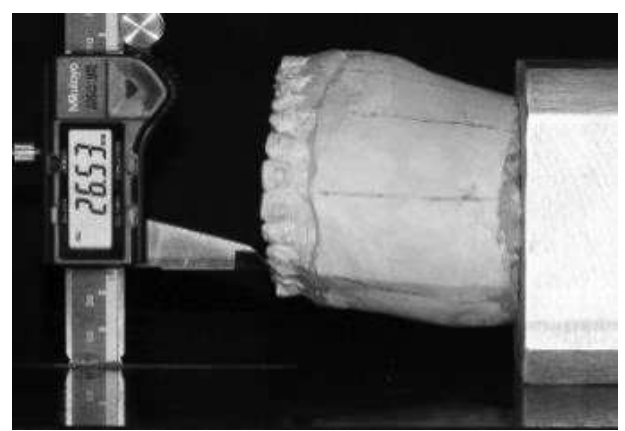

(C3)

Figura 1 - Medidas tridimensionais dos modelos laboratoriais (pré-operatório). Medida vertical: (A1) - linha média/ (A2) - elemento 16 / (A3) - elemento 26. Medida horizontal: (B1) - linha média/ (B2) - elemento 16 / (B3) - elemento 26. Medida transversal: (C1) - linha média/ (C2) - elemento 16 / (C3) - elemento 26. 
A montagem em articulador semi-ajustável (pré-operatória) foi posicionada na Mesa de Erickson para medida da dimensão vertical do arco superior - maxila (Figura 2). Vale ressaltar que o pino incisal não é fidedigno para o controle da dimensão vertical, e foi utilizado portanto, ponto de referência na LMS.

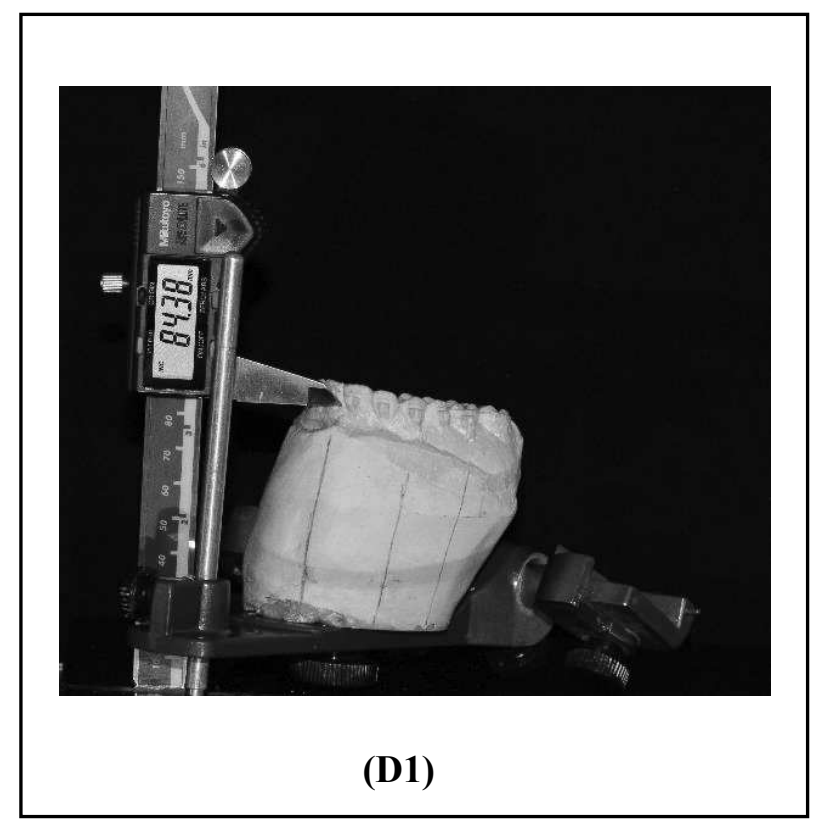

Figura 2 - Medida da dimensão vertical pré-operatória: (D1) Medida vertical inicial na região da linha média superior (LMS). Posicionou-se o articulador semi-ajustável (ASA) em posição invertida com pino incisal em contato passivo com a Mesa de Erickson.

Em seguida, foram realizadas diferentes simulações do reposicionamento maxilar (explicitadas na Tabela 1) e obtido e impresso 01 guia cirúrgico para cada simulação. Durante o planejamento virtual foi obtido o Overjet de cada paciente no programa Dolphin Imaging $11.9^{\circledR}$, e a medida foi comparada à da montagem em Articulador Semi-Ajustável (ASA) aferida manualmente por meio de compasso ponta seca. 
Tabela 1 - Movimentações maxilares avaliadas no estudo.

\begin{tabular}{cc}
\hline DIREÇÃO & MAXILA \\
\hline Grupo 1 - AVANÇO & $\mathbf{3 m m}$ \\
\hline Irupo 2 - REPOSICIONAMENTO SUPERIOR (RS) & $\mathbf{6 m m}$ \\
\hline INCISIVOS & $\mathbf{6 m m}$ \\
\hline Grupo 3 - REPOSICIONAMENTO SUPERIOR (RS) & $\mathbf{3 m m}$ \\
\hline Grupo 4 - LINHA MÉDIA & $\mathbf{6 m m}$ \\
\hline INCISIVOS & $\mathbf{3 m m}$ \\
\hline Grupo 5 - REPOSICIONAMENTO INFERIOR (RI) & $\mathbf{6 m m}$ \\
\hline Grupo 8 - AVANÇO + RI INCISIVOS + RS MOLARES & $\mathbf{6 m m}+\mathbf{3 m m}+\mathbf{3 m m}$ \\
\hline Grupo 6 - REPOSICIONAMENTO INFERIOR (RI) & $\mathbf{6 m m}$ \\
\hline DOS MOLARES & $\mathbf{3 m m}$ \\
\hline
\end{tabular}

Por fim, os modelos superiores (maxilares) foram então separados da plataforma de montagem, o guia cirúrgico posicionado entre as arcadas e o modelo fixado com massa de modelar (neste momento o ramo inferior do ASA toca corretamente o ramo superior na região condilar). Realizou-se o controle da dimensão vertical (vide Figura 3 a seguir). 


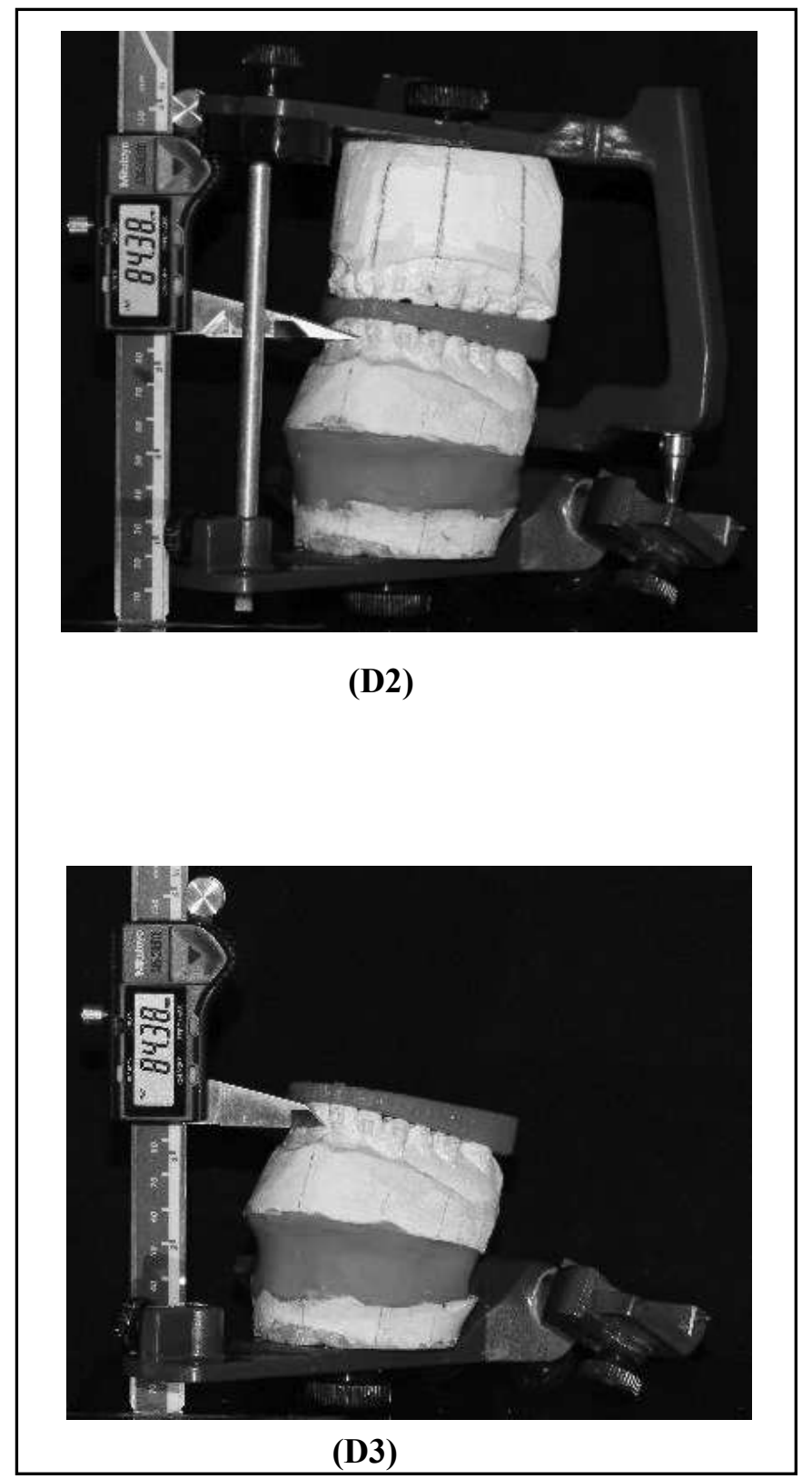

Figura 3 - Medida da dimensão vertical após interposição do guia cirúrgico. Posicionou-se o articulador semiajustável (ASA) em posição invertida e realizou-se as seguintes medidas: (D2) Medida vertical após posicionamento do guia cirúrgico - fixou-se lâmina de bisturi ${ }^{\circ} 11$ na extremidade do paquímetro para medida devido interferências do ramo inferior do articulador; e (D3) Medida vertical conferida sem a lâmina de bisturi $\mathrm{n}^{\circ} 11$ e o ramo inferior do articulador. 
Os resultados por fim, foram verificados na Mesa de Erickson e comparados com a movimentação planejada (Figura 4).

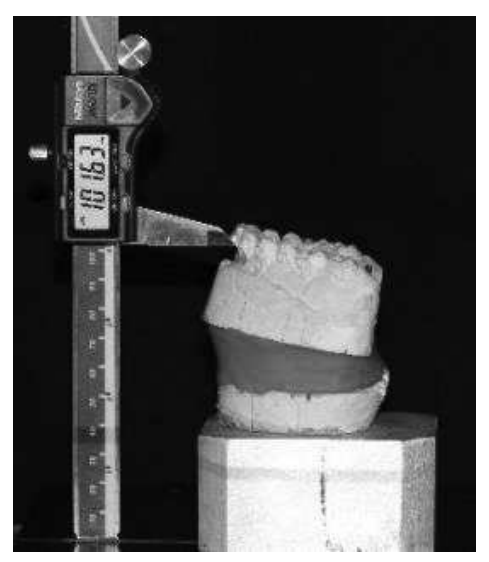

(A1)

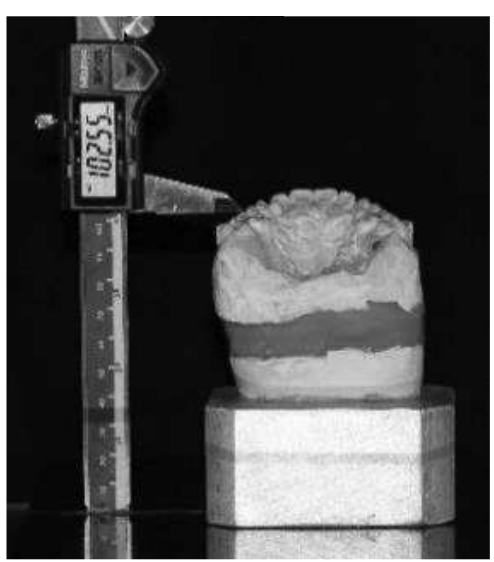

(A2)

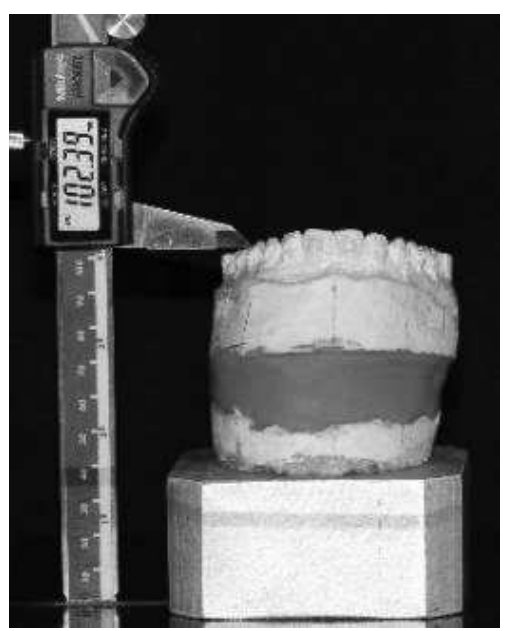

(A3)

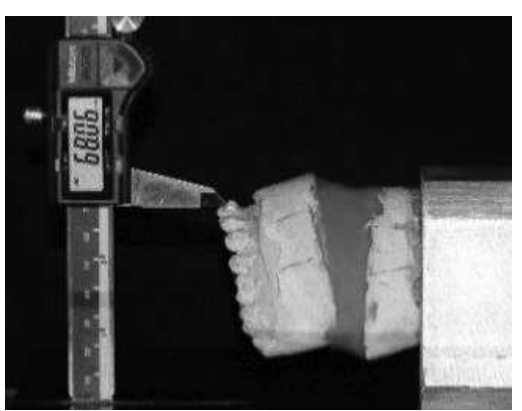

(B1)

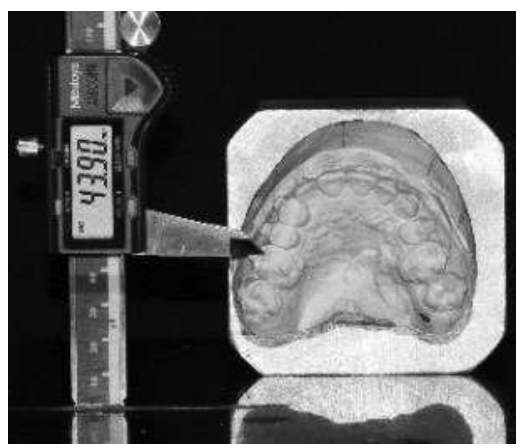

(B2)

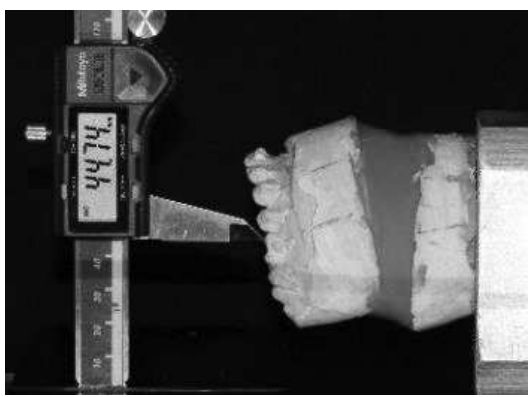

(B3)

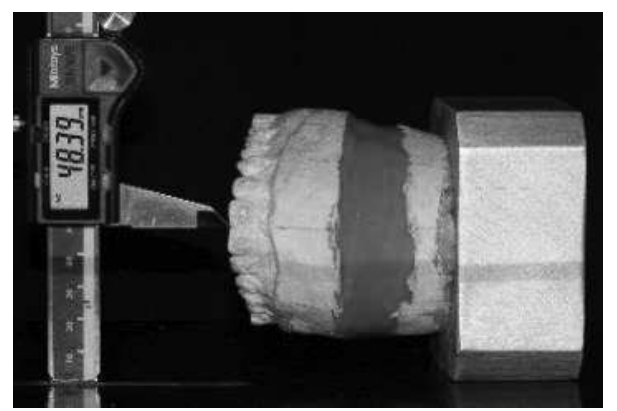

(C1)

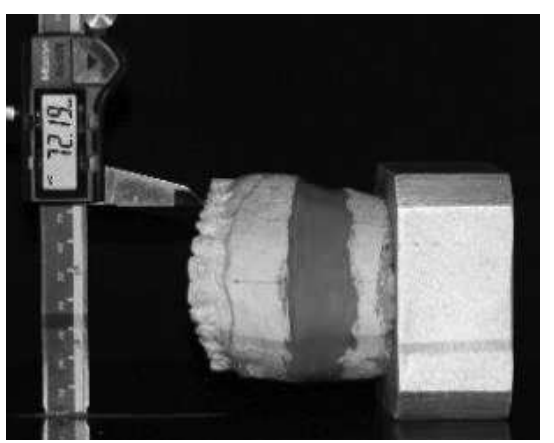

(C2)

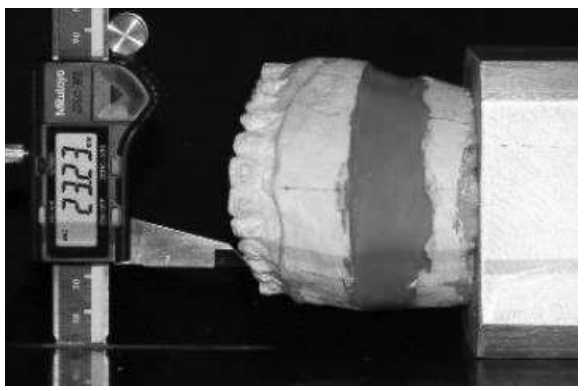

(C3)

Figura 4 - Medidas tridimensionais dos modelos laboratoriais (após posicionamento do guia cirúrgico). Medida vertical: (A1) - linha média/ (A2) - elemento 26 / (A3) - elemento 16. Medida horizontal: (B1) - linha média/ (B2) - elemento 16 / (B3) - elemento 26. Medida transversal: (C1) - linha média/ (C2) - elemento 16 / (C3) elemento 26. 
As etapas do estudo estão resumidas na Tabela 2 abaixo.

Tabela 2 - Etapas do estudo

\section{ETAPAS DO ESTUDO}

\section{1- Seleção dos prontuários}

2- Obtenção dos modelos laboratoriais e medições pré-operatórias na Mesa de

\section{Erickson}

3- Avaliação de imagens, escaneamento e simulação cirúrgica virtual

4- Impressão dos guias cirúrgicos virtuais

5-Recorte dos modelos, posicionamento dos guias, fixação e medições pósoperatórias $\left(\mathrm{T}_{2}\right)$ na Mesa de Erickson

6 -Comparação dos valores encontrados em com os valores planejados $\left(T_{1}\right)$

\subsection{Metodologia para aquisição da imagem}

As TCFC da face utilizadas foram adquiridas seguindo os parâmetros para posicionamento do paciente e padronização da aquisição da imagem adotados pelo Curso de Residência em Cirurgia e Traumatologia Buco-Maxilo-Faciais da Faculdade de Odontologia de Ribeirão Preto - USP:

- Imagem adquirida por meio do mesmo modelo de tomógrafo;

- Paciente com lábios em repouso, orientado a não deglutir durante a aquisição da imagem;

- Oclusão em Relação Cêntrica;

- Cabeça posicionada com Plano de Frankfurt paralelo ao solo;

- Imagem adquirida da glabela ao hióide, incluindo articulações têmporo-mandibulares (ATM's) e vias aéreas;

- Gravação em CD no formato DICOM. 


\section{RESULTADOS}

O presente estudo teve amostra de oito pacientes (cinco homens e três mulheres) com idade média de 33 anos (variou de 22 a 47 anos). Foi selecionado 01 paciente para cada grupo de acordo com os critérios de inclusão e exclusão. Ao final, realizou-se 14 movimentações diferentes em simulação virtual pelo mesmo operador. $(n=14)$.

O diagnóstico pré-operatório dos pacientes da amostra é explicitado na Tabela 3 abaixo.

Tabela 3 - Diagnóstico pré-operatório

\begin{tabular}{lll}
\hline Diagnóstico & $\mathbf{N}^{\mathbf{0}}$ de pacientes & \% de pacientes \\
\hline Classe II & 5 & 62.5 \\
\hline Classe III & 3 & 37.5 \\
\hline
\end{tabular}

Conforme observa-se na Tabela 3 acima, a maioria dos pacientes apresentava deformidade dentofacial Classe II (62.5\% dos pacientes).

A seguir, seguem as Tabelas (4 a 17) que apresentam os dados obtidos em cada Grupo de movimentações. Vale ressaltar que os números em cor Azul representam os valores a serem encontrados de acordo com o planejamento no Programa Dolphin Imaging $11.9^{\circledR}$. Os números em vermelho representam os valores encontrados na Mesa de Erickson. Cada medida foi realizada três vezes consecutivas.

Nas Tabelas 4 e 5 a seguir observa-se as medidas obtidas pelo pesquisador por meio do programa Dolhpin Imaging $11.9^{\circledR}$ e da Mesa de Erickson (ME) para o Grupo 1. 
Tabela 4 - Resultados Grupo 1 - AVANÇO (3mm)

\begin{tabular}{|c|c|c|c|c|c|c|c|c|c|}
\hline \multirow{2}{*}{$\begin{array}{l}\text { MOVIMENTAÇÃO } \\
\text { DA MAXILA: } \\
\text { MEDIDA } \\
\text { VERTICAL }\end{array}$} & \multicolumn{9}{|c|}{ Grupo 1 - AVANÇO 3MM } \\
\hline & & LMS & & & 16 & & & 26 & \\
\hline $\begin{array}{l}\text { INICIAL ME* } \\
1,2 \text { e } 3\end{array}$ & 96.13 & 96.13 & 96.14 & 98.29 & 98.29 & 98.31 & 96.30 & 96.48 & 96.31 \\
\hline INICIAL (MÉDIA) & & 96.13 & & & 98.29 & & & 96.36 & \\
\hline FINAL DOLPHIN & & 96.13 & & & 98.29 & & & 96.36 & \\
\hline $\begin{array}{l}\text { FINAL ME* } \\
1,2 \text { e } 3\end{array}$ & 96.15 & 96.10 & 96.17 & 98.33 & 98.26 & 98.34 & 96.34 & 96.41 & 96.40 \\
\hline MÉDIA ME* & & 96.14 & & & 98.31 & & & 96.38 & \\
\hline $\begin{array}{l}\text { MEDIDA } \\
\text { HORIZONTAL }\end{array}$ & & LMS & & & 16 & & & 26 & \\
\hline $\begin{array}{l}\text { INICIAL ME* } \\
1,2 \text { e } 3\end{array}$ & 65.47 & 65.50 & 65.51 & 37.40 & 37.42 & 37.42 & 37.83 & 37.85 & 37.88 \\
\hline INICIAL (MÉDIA) & & 65.49 & & & 37.41 & & & 37.85 & \\
\hline FINAL DOLPHIN & $65.49+3$ & $68.49 * *$ & & $37.41+3$ & $40.41 * *$ & & $37.85+3$ & $40.85 * *$ & \\
\hline $\begin{array}{l}\text { FINAL ME* } \\
1,2 \text { e } 3\end{array}$ & 68.45 & 68.48 & 68.53 & 40.38 & 40.45 & 40.46 & 40.80 & 40.88 & 40.81 \\
\hline MÉDIA ME* & & 68.49 & & & 40.43 & & & 40.83 & \\
\hline $\begin{array}{l}\text { MEDIDA } \\
\text { TRANSVERSA } \\
\text { (APOIO D) }\end{array}$ & & LMS & & & 16 & & & 26 & \\
\hline $\begin{array}{l}\text { INICIAL ME* } \\
1,2 \text { e } 3\end{array}$ & 39.12 & 39.12 & 39.11 & 15.54 & 15.55 & 15.55 & 66.49 & 66.51 & 66.51 \\
\hline INICIAL (MÉDIA) & & 39.11 & & & 15.54 & & & 66.50 & \\
\hline FINAL DOLPHIN & & 39.11 & & & 15.54 & & & 66.50 & \\
\hline $\begin{array}{l}\text { FINAL ME* } \\
1,2 \text { e } 3\end{array}$ & 38.95 & 39.16 & 39.12 & 15.50 & 15.52 & 15.53 & 66.49 & 66.55 & 66.52 \\
\hline MÉDIA ME* & & 39.08 & & & 15.52 & & & 66.52 & \\
\hline
\end{tabular}

*ME - Mesa de Erickson.

**Medida prevista pelo programa Dolphin Imaging $11.9^{\circledR}$ após a movimentação da maxila.

Azul - valores a serem encontrados de acordo com o Programa Dolphin Imaging 11.9 ${ }^{\circledR}$.

Vermelho - valores encontrados na Mesa de Erickson.

Na Tabela 4 acima observa-se que os resultados encontrados para o Grupo 1 (avanço de $3 \mathrm{~mm}$ ) indicam exatidão no posicionamento da Linha Média Superior (LMS) em sua medida horizontal. A maior diferença encontrada entre os planejamentos foi de $0,03 \mathrm{~mm}$, na medida transversa da LMS. 
Tabela 5 - Resultados Grupo 1 - AVANÇO (6mm)

\begin{tabular}{|c|c|c|c|c|c|c|c|c|c|}
\hline $\begin{array}{l}\text { MOVIMENTAÇÃO } \\
\text { DA MAXILA: }\end{array}$ & \multicolumn{9}{|c|}{ Grupo 1 - AVANÇO 6MM } \\
\hline $\begin{array}{l}\text { MEDIDA } \\
\text { VERTICAL }\end{array}$ & & LMS & & & 16 & & & 26 & \\
\hline $\begin{array}{l}\text { INICIAL ME* } \\
1,2 \text { e } 3\end{array}$ & 96.13 & 96.13 & 96.14 & 98.29 & 98.29 & 98.31 & 96.30 & 96.48 & 96.31 \\
\hline INICIAL (MÉDIA) & & 96.13 & & & 98.29 & & & 96.36 & \\
\hline FINAL DOLPHIN & & 96.13 & & & 98.29 & & & 96.36 & \\
\hline $\begin{array}{l}\text { FINAL ME* } \\
1,2 \text { e } 3\end{array}$ & 96.12 & 96.18 & 96.16 & 98.35 & 98.32 & 98.30 & 96.35 & 96.43 & 96.36 \\
\hline MÉDIA ME* & & 96.15 & & & 98.32 & & & 96.38 & \\
\hline $\begin{array}{l}\text { MEDIDA } \\
\text { HORIZONTAL }\end{array}$ & & LMS & & & 16 & & & 26 & \\
\hline $\begin{array}{l}\text { INICIAL ME* } \\
1,2 \text { e } 3\end{array}$ & 65.47 & 65.50 & 65.51 & 37.40 & 37.42 & 37.42 & 37.83 & 37.85 & 37.88 \\
\hline INICIAL (MÉDIA) & & 65.49 & & & 37.41 & & & 37.85 & \\
\hline FINAL DOLPHIN & $65.49+6$ & $71.49 * *$ & & $37.41+6$ & $43.41 * *$ & & $37.85+6$ & $43.85 * *$ & \\
\hline $\begin{array}{l}\text { FINAL ME* } \\
1,2 \text { e } 3\end{array}$ & 71.38 & 71.44 & 71.32 & 43.32 & 43.35 & 43.43 & 43.68 & 43.77 & 43.80 \\
\hline MÉDIA ME* & & 71.38 & & & 43.37 & & & 43.75 & \\
\hline $\begin{array}{l}\text { MEDIDA } \\
\text { TRANSVERSA } \\
\text { (APOIO D) }\end{array}$ & & LMS & & & 16 & & & 26 & \\
\hline $\begin{array}{l}\text { INICIAL ME* } \\
1,2 \text { e } 3\end{array}$ & 39.12 & 39.12 & 39.11 & 15.54 & 15.55 & 15.55 & 66.49 & 66.51 & 66.51 \\
\hline INICIAL (MÉDIA) & & 39.11 & & & 15.54 & & & 66.50 & \\
\hline FINAL DOLPHIN & & 39.11 & & & 15.54 & & & 66.50 & \\
\hline $\begin{array}{l}\text { FINAL ME* } \\
1,2 \text { e } 3\end{array}$ & 38.94 & 38.99 & 39.06 & 15.49 & 15.51 & 15.45 & 66.48 & 66.54 & 66.49 \\
\hline MÉDIA ME* & & 39.00 & & & 15.48 & & & 66.50 & \\
\hline
\end{tabular}

*ME - Mesa de Erickson.

**Medida prevista pelo programa Dolphin Imaging $11.9^{\circledR}$ após a movimentação da maxila.

Azul - valores a serem encontrados de acordo com o Programa Dolphin Imaging 11.9 ${ }^{\circledR}$.

Vermelho - valores encontrados na Mesa de Erickson.

Os resultados da Tabela 5 (avanço de $6 \mathrm{~mm}$ ) acima evidenciam uma diferença numérica máxima de $0,11 \mathrm{~mm}$ entre o Dolphin Imaging $11.9^{\circledR}$ e a Mesa de Erickson, encontrada nas medidas horizontal e transversa da LMS.

Nas Tabelas 6 e 7 observa-se as medidas obtidas pelo pesquisador para o Grupo 2REPOSICIONAMENTO SUPERIOR INCISIVOS (3 e 6mm). 
Tabela 6 - Resultados Grupo 2 - REPOSICIONAMENTO SUPERIOR INCISIVOS (3mm) MOVIMENTAÇÃO Grupo 2 - REPOSICIONAMENTO SUPERIOR INCISIVOS 3MM DA MAXILA:

\begin{tabular}{|c|c|c|c|c|c|c|c|c|c|}
\hline $\begin{array}{l}\text { MEDIDA } \\
\text { VERTICAL }\end{array}$ & & LMS & & & 16 & & & 26 & \\
\hline $\begin{array}{l}\text { INICIAL ME* } \\
1,2 \text { e } 3\end{array}$ & 97.50 & 97.53 & 97.55 & 111.69 & 111.73 & 111.71 & 103.81 & 103.85 & 103.82 \\
\hline INICIAL (MÉDIA) & & 97.52 & & & 111.71 & & & 103.82 & \\
\hline FINAL DOLPHIN & $\begin{array}{l}97.52- \\
3.00\end{array}$ & $94.52 * *$ & & $\begin{array}{c}111.71- \\
0.98\end{array}$ & $110.73 * *$ & & $\begin{array}{c}103.82- \\
1.05\end{array}$ & $102.77 * *$ & \\
\hline $\begin{array}{l}\text { FINAL ME* } \\
1,2 \text { e } 3\end{array}$ & 94.63 & 94.62 & 94.65 & 110.55 & 110.52 & 110.47 & 102.45 & 102.48 & 102.43 \\
\hline MÉDIA ME* & & 94.63 & & & 110.51 & & & 102.45 & \\
\hline $\begin{array}{l}\text { MEDIDA } \\
\text { HORIZONTAL }\end{array}$ & & LMS & & & 16 & & & 26 & \\
\hline $\begin{array}{l}\text { INICIAL ME* } \\
1,2 \text { e } 3\end{array}$ & 70.08 & 70.04 & 69.98 & 40.57 & 40.63 & 40.61 & 38.60 & 38.65 & 38.63 \\
\hline INICIAL (MÉDIA) & & 70.03 & & & 40.60 & & & 38.62 & \\
\hline FINAL DOLPHIN & & 70.03 & & $\begin{array}{l}40.60- \\
0.22\end{array}$ & $40.38 * *$ & & $\begin{array}{c}38.62- \\
0.13\end{array}$ & $38.49 * *$ & \\
\hline $\begin{array}{l}\text { FINAL ME* } \\
1,2 \text { e } 3\end{array}$ & 69.96 & 69.92 & 69.91 & 40.20 & 40.25 & 40.22 & 38.20 & 38.13 & 38.16 \\
\hline MÉDIA ME* & & 69.93 & & & 40.22 & & & 38.16 & \\
\hline $\begin{array}{l}\text { MEDIDA } \\
\text { TRANSVERSA } \\
\text { (APOIO D) }\end{array}$ & & LMS & & & 16 & & & 26 & \\
\hline $\begin{array}{l}\text { INICIAL ME* } \\
1,2 \text { e } 3\end{array}$ & 41.31 & 41.32 & 41.29 & 16.83 & 16.87 & 16.90 & 66.84 & 66.89 & 66.93 \\
\hline INICIAL (MÉDIA) & & 41.30 & & & 16.86 & & & 66.88 & \\
\hline FINAL DOLPHIN & & 41.30 & & & 16.86 & & & 66.88 & \\
\hline $\begin{array}{l}\text { FINAL ME* } \\
1,2 \text { e } 3\end{array}$ & 41.25 & 41.27 & 41.24 & 16.85 & 16.82 & 16.78 & 66.83 & 66.85 & 66.91 \\
\hline MÉDIA ME* & & 41.25 & & & 16.81 & & & 66.86 & \\
\hline
\end{tabular}

*ME - Mesa de Erickson.

**Medida prevista pelo programa Dolphin Imaging $11.9^{\circledR}$ após a movimentação da maxila.

Azul - valores a serem encontrados de acordo com o Programa Dolphin Imaging 11.9 ${ }^{\circledR}$.

Vermelho - valores encontrados na Mesa de Erickson.

O Grupo 2 (reposicionamento superior de incisivos em $3 \mathrm{~mm}$ ) apresentou resultados muito próximos entre o planejamento virtual 3D e a Mesa de Erickson, e a maior diferença foi encontrada na medida horizontal do elemento 26: 0,33mm. Já na Tabela 7 a seguir, no Grupo 2 (reposicionamento superior de incisivos em $6 \mathrm{~mm}$ ) a maior divergência de valores encontrada foi de $0,41 \mathrm{~mm}$, nas medidas verticais dos elementos 16 e 26 . 
Tabela 7 - Resultados Grupo 2 - REPOSICIONAMENTO SUPERIOR INCISIVOS (6mm)

\begin{tabular}{|c|c|c|c|c|c|c|c|c|c|}
\hline $\begin{array}{l}\text { MOVIMENTAÇÃO } \\
\text { DA MAXILA: }\end{array}$ & \multicolumn{9}{|c|}{ Grupo 2 - REPOSICIONAMENTO SUPERIOR INCISIVOS 6MM } \\
\hline $\begin{array}{l}\text { MEDIDA } \\
\text { VERTICAL }\end{array}$ & \multicolumn{3}{|c|}{ LMS } & \multicolumn{3}{|c|}{16} & \multicolumn{3}{|c|}{26} \\
\hline $\begin{array}{l}\text { INICIAL ME* } \\
1,2 \text { e } 3\end{array}$ & 97.50 & 97.53 & 97.55 & 111.69 & 111.73 & 111.71 & 103.81 & 103.85 & 103.82 \\
\hline INICIAL (MÉDIA) & & 97.52 & & & 111.71 & & & 103.82 & \\
\hline FINAL DOLPHIN & $\begin{array}{l}97.52 \\
-6.00\end{array}$ & $91.52 * *$ & & $\begin{array}{c}111.71 \\
-1.65\end{array}$ & $110.06 * *$ & & $\begin{array}{c}103.82 \\
-1.81\end{array}$ & $102.01 * *$ & \\
\hline $\begin{array}{l}\text { FINAL ME* } \\
1,2 \text { e } 3\end{array}$ & 91.37 & 91.33 & 91.30 & 109.62 & 109.66 & 109.69 & 101.58 & 101.63 & 101.60 \\
\hline MÉDIA ME* & & 91.33 & & & 109.65 & & & 101.60 & \\
\hline
\end{tabular}

\begin{tabular}{|c|c|c|c|c|c|c|c|c|c|}
\hline $\begin{array}{l}\text { MEDIDA } \\
\text { HORIZONTAL }\end{array}$ & & LMS & & & 16 & & & 26 & \\
\hline $\begin{array}{l}\text { INICIAL ME* } \\
1,2 \text { e } 3\end{array}$ & 70.08 & 70.04 & 69.98 & 40.57 & 40.63 & 40.61 & 38.60 & 38.65 & 38.63 \\
\hline INICIAL (MÉDIA) & & 70.03 & & & 40.60 & & & 38.62 & \\
\hline FINAL DOLPHIN & & 70.03 & & $\begin{array}{c}40.60- \\
0.30\end{array}$ & $40.30 * *$ & & $\begin{array}{c}38.62- \\
0.11\end{array}$ & $38.51 * *$ & \\
\hline $\begin{array}{l}\text { FINAL ME* } \\
1,2 \text { e } 3\end{array}$ & 70.11 & 70.15 & 70.07 & 40.47 & 40.51 & 40.45 & 38.75 & 38.72 & 38.77 \\
\hline MÉDIA ME* & & 70.11 & & & 40.47 & & & 38.74 & \\
\hline
\end{tabular}

\begin{tabular}{|c|c|c|c|c|c|c|c|c|c|}
\hline $\begin{array}{l}\text { MEDIDA } \\
\text { TRANSVERSA } \\
\text { (APOIO D) }\end{array}$ & & LMS & & & 16 & & \multicolumn{3}{|c|}{26} \\
\hline $\begin{array}{l}\text { INICIAL ME* } \\
1,2 \text { e } 3\end{array}$ & 41.31 & 41.32 & 41.29 & 16.83 & 16.87 & 16.90 & 66.84 & 66.89 & 66.93 \\
\hline INICIAL (MÉDIA) & & 41.30 & & & 16.86 & & & 66.88 & \\
\hline FINAL DOLPHIN & & 41.30 & & & 16.86 & & & 66.88 & \\
\hline $\begin{array}{l}\text { FINAL ME* } \\
1,2 \text { e } 3\end{array}$ & 41.23 & 41.26 & 41.20 & 16.67 & 16.71 & 16.76 & 66.87 & 66.92 & 66.95 \\
\hline MÉDIA ME* & & 41.23 & & & 16.71 & & & 66.91 & \\
\hline
\end{tabular}

*ME - Mesa de Erickson.

**Medida prevista pelo programa Dolphin Imaging $11.9^{\circledR}$ após a movimentação da maxila.

Azul - valores a serem encontrados de acordo com o Programa Dolphin Imaging 11.9 ${ }^{\circledR}$.

Vermelho - valores encontrados na Mesa de Erickson.

Nas Tabelas 8 e 9 seguem os resultados do Grupo 3- REPOSICIONAMENTO SUPERIOR MOLARES (3 e 6mm). 
Tabela 8 - Resultados Grupo 3 - REPOSICIONAMENTO SUPERIOR MOLARES (3mm) MOVIMENTAÇÃO Grupo 3 - REPOSICIONAMENTO SUPERIOR MOLARES 3MM DA MAXILA:

\begin{tabular}{|c|c|c|c|c|c|c|c|c|c|}
\hline MEDIDA & & LMS & & & 16 & & & 26 & \\
\hline $\begin{array}{l}\text { INICIAL ME* } \\
1,2 \text { e } 3\end{array}$ & 102.72 & 102.70 & 102.74 & 102.65 & 102.64 & 102.66 & 99.84 & 99.86 & 99.83 \\
\hline INICIAL (MÉDIA) & & 102.72 & & & 102.65 & & & 99.84 & \\
\hline FINAL DOLPHIN & & 102.72 & & $\begin{array}{c}102.65 \\
-3.00\end{array}$ & $99.65 * *$ & & $\begin{array}{c}98.84- \\
3.15\end{array}$ & $96.69 * *$ & \\
\hline $\begin{array}{l}\text { FINAL ME* } \\
1,2 \text { e } 3\end{array}$ & 102.65 & 102.70 & 102.71 & 99.47 & 99.45 & 99.49 & 96.48 & 96.46 & 96.43 \\
\hline MÉDIA ME* & & 102.68 & & & 99.47 & & & 96.45 & \\
\hline $\begin{array}{l}\text { MEDIDA } \\
\text { HORIZONTAL }\end{array}$ & & LMS & & & 16 & & & 26 & \\
\hline $\begin{array}{l}\text { INICIAL ME* } \\
1,2 \text { e } 3\end{array}$ & 59.07 & 59.05 & 59.08 & 27.11 & 27.09 & 27.12 & 29.45 & 29.43 & 29.47 \\
\hline INICIAL (MÉDIA) & & 59.06 & & & 27.10 & & & 29.45 & \\
\hline FINAL DOLPHIN & & 59.06 & & $\begin{array}{l}27.10 \\
+0.48 \\
\end{array}$ & $27.58 * *$ & & $\begin{array}{r}29.45 \\
+0.50 \\
\end{array}$ & $29.95 * *$ & \\
\hline $\begin{array}{l}\text { FINAL ME* } \\
1,2 \text { e } 3\end{array}$ & 59.05 & 59.02 & 59.01 & 27.39 & 27.37 & 27.37 & 29.74 & 29.78 & 29.79 \\
\hline MÉDIA ME* & & 59.02 & & & 27.37 & & & 29.77 & \\
\hline
\end{tabular}

\begin{tabular}{|c|c|c|c|c|c|c|c|c|c|}
\hline $\begin{array}{l}\text { MEDIDA } \\
\text { TRANSVERSA } \\
\text { (APOIO D) }\end{array}$ & & LMS & & & 16 & & \multicolumn{3}{|c|}{26} \\
\hline $\begin{array}{l}\text { INICIAL ME* } \\
1,2 \text { e } 3\end{array}$ & 37.66 & 37.67 & 37.64 & 13.91 & 13.89 & 13.93 & 65.78 & 65.76 & 65.79 \\
\hline INICIAL (MÉDIA) & & 37.65 & & & 13.91 & & & 65.77 & \\
\hline FINAL DOLPHIN & & 37.65 & & & 13.91 & & & 65.77 & \\
\hline $\begin{array}{l}\text { FINAL ME* } \\
1,2 \text { e } 3\end{array}$ & 37.58 & 37.62 & 37.63 & 13.95 & 13.91 & 14.03 & 65.72 & 65.85 & 65.78 \\
\hline MÉDIA ME* & & 37.61 & & & 13.96 & & & 65.78 & \\
\hline
\end{tabular}

*ME - Mesa de Erickson.

**Medida prevista pelo programa Dolphin Imaging $11.9^{\circledR}$ após a movimentação da maxila. Azul - valores a serem encontrados de acordo com o Programa Dolphin Imaging 11.9 ${ }^{\circledR}$. Vermelho - valores encontrados na Mesa de Erickson.

Na Tabela 8 acima observa-se que os resultados encontrados para o Grupo 3 (reposicionamento superior de molares em $3 \mathrm{~mm}$ ) indicam maiores divergências na medida vertical: de $0,18 \mathrm{~mm}$ no elemento 16 e $0,24 \mathrm{~mm}$ no elemento 26 . 
Tabela 9 - Resultados Grupo 3 - REPOSICIONAMENTO SUPERIOR MOLARES (6mm)

MOVIMENTAÇÃO Grupo 3 - REPOSICIONAMENTO SUPERIOR MOLARES 6MM DA MAXILA:

\begin{tabular}{|c|c|c|c|c|c|c|c|c|c|}
\hline MEDIDA & & LMS & & & 16 & & & 26 & \\
\hline $\begin{array}{l}\text { INICIAL ME* } \\
1,2 \text { e } 3\end{array}$ & 102.72 & 102.70 & 102.74 & 102.65 & 102.64 & 102.66 & 99.84 & 99.86 & 99.83 \\
\hline INICIAL (MÉDIA) & & 102.72 & & & 102.65 & & & 99.84 & \\
\hline FINAL DOLPHIN & & 102.72 & & $\begin{array}{l}102.65 \\
-6.00\end{array}$ & $96.65 * *$ & & $\begin{array}{l}99.84 \\
-6.30\end{array}$ & $93.54 * *$ & \\
\hline $\begin{array}{l}\text { FINAL ME* } \\
1,2 \text { e } 3\end{array}$ & 102.63 & 102.68 & 102.66 & 96.38 & 96.41 & 96.43 & 93.26 & 93.30 & 93.32 \\
\hline MÉDIA ME* & & 102.65 & & & 96.40 & & & 93.29 & \\
\hline $\begin{array}{l}\text { MEDIDA } \\
\text { HORIZONTAL }\end{array}$ & & LMS & & & 16 & & & 26 & \\
\hline $\begin{array}{l}\text { INICIAL ME* } \\
1,2 \text { e } 3\end{array}$ & 59.07 & 59.05 & 59.08 & 27.11 & 27.09 & 27.12 & 29.45 & 29.43 & 29.47 \\
\hline INICIAL (MÉDIA) & & 59.06 & & & 27.10 & & & 29.45 & \\
\hline FINAL DOLPHIN & & 59.06 & & $\begin{array}{r}27.10 \\
+1.31 \\
\end{array}$ & $28.41 * *$ & & $\begin{array}{r}29.45 \\
+1.37\end{array}$ & $30.82 * *$ & \\
\hline $\begin{array}{l}\text { FINAL ME* } \\
1,2 \text { e } 3\end{array}$ & 59.05 & 59.01 & 59.04 & 28.33 & 28.30 & 28.29 & 30.68 & 30.71 & 30.74 \\
\hline MÉDIA ME* & & 59.03 & & & 28.30 & & & 30.71 & \\
\hline $\begin{array}{l}\text { MEDIDA } \\
\text { TRANSVERSA } \\
\text { (APOIO D) }\end{array}$ & & LMS & & & 16 & & & 26 & \\
\hline $\begin{array}{l}\text { INICIAL ME* } \\
1,2 \text { e } 3\end{array}$ & 37.66 & 37.67 & 37.64 & 13.91 & 13.89 & 13.93 & 65.78 & 65.76 & 65.79 \\
\hline INICIAL (MÉDIA) & & 37.65 & & & 13.91 & & & 65.77 & \\
\hline FINAL DOLPHIN & & 37.65 & & & 13.91 & & & 65.77 & \\
\hline $\begin{array}{l}\text { FINAL ME* } \\
1,2 \text { e } 3\end{array}$ & 37.59 & 37.64 & 37.55 & 13.87 & 13.96 & 13.90 & 65.88 & 65.77 & 65.86 \\
\hline MÉDIA ME* & & 37.59 & & & 13.91 & & & 65.83 & \\
\hline
\end{tabular}

*ME - Mesa de Erickson.

**Medida prevista pelo programa Dolphin Imaging $11.9^{\circledR}$ após a movimentação da maxila.

Azul - valores a serem encontrados de acordo com o Programa Dolphin Imaging 11.9 ${ }^{\circledR}$.

Vermelho - valores encontrados na Mesa de Erickson.

Os resultados da Tabela 9 acima demonstram que o Grupo 3 (reposicionamento superior de molares em 6mm) apresentou exatidão na medida transversa do elemento 16. A maior diferença encontrada foi de $0,25 \mathrm{~mm}$ na medida vertical dos elementos 16 e 26 .

A seguir, nas Tabelas 10 e 11 são demonstrados os resultados para o Grupo 4 - LINHA MÉDIA (3 e 6mm). 
Tabela 10 - Resultados Grupo 4 - LINHA MÉDIA (3mm)

\begin{tabular}{|c|c|c|c|c|c|c|c|c|c|}
\hline MOVIMENTAÇÃO & \multicolumn{9}{|c|}{ Grupo 4 - LINHA MÉDIA 3MM } \\
\hline MEDIDA & & LMS & & & 16 & & & 26 & \\
\hline $\begin{array}{l}\text { INICIAL ME* } \\
1,2 \text { e } 3\end{array}$ & 92.21 & 92.19 & 92.17 & 93.70 & 93.65 & 93.64 & 97.33 & 97.27 & 97.25 \\
\hline INICIAL (MÉDIA) & & 92.19 & & & 93.66 & & & 97.28 & \\
\hline FINAL DOLPHIN & & 92.19 & & & 93.66 & & & 97.28 & \\
\hline $\begin{array}{l}\text { FINAL ME* } \\
1,2 \text { e } 3\end{array}$ & 92.17 & 92.12 & 92.14 & 93.61 & 93.59 & 93.63 & 97.23 & 97.22 & 97.25 \\
\hline MÉDIA ME* & & 92.14 & & & 93.61 & & & 97.23 & \\
\hline $\begin{array}{l}\text { MEDIDA } \\
\text { HORIZONTAL }\end{array}$ & & LMS & & & 16 & & & 26 & \\
\hline $\begin{array}{l}\text { INICIAL ME* } \\
1,2 \text { e } 3\end{array}$ & 54.80 & 54.86 & 54.84 & 25.29 & 25.32 & 25.30 & 24.45 & 24.49 & 24.48 \\
\hline INICIAL (MÉDIA) & & 54.83 & & & 25.30 & & & 24.47 & \\
\hline FINAL DOLPHIN & & 54.83 & & & 25.30 & & & 24.47 & \\
\hline $\begin{array}{l}\text { FINAL ME* } \\
1,2 \text { e } 3\end{array}$ & 54.79 & 54.86 & 54.80 & 25.23 & 25.26 & 25.27 & 24.44 & 24.50 & 24.52 \\
\hline MÉDIA ME* & & 54.81 & & & 25.25 & & & 24.48 & \\
\hline $\begin{array}{l}\text { MEDIDA } \\
\text { TRANSVERSA } \\
\text { (APOIO D) }\end{array}$ & & LMS & & & 16 & & & 26 & \\
\hline $\begin{array}{l}\text { INICIAL ME* } \\
1,2 \text { e } 3\end{array}$ & 36.15 & 36.12 & 36.09 & 13.21 & 13.18 & 13.19 & 59.35 & 59.38 & 59.32 \\
\hline INICIAL (MÉDIA) & & 36.12 & & & 13.19 & & & 59.35 & \\
\hline FINAL DOLPHIN & $\begin{array}{l}36.12 \\
-3.00\end{array}$ & $33.12 * *$ & & $\begin{array}{r}13.19 \\
-3.00\end{array}$ & $10.19 * *$ & & $\begin{array}{l}59.35 \\
-3.00\end{array}$ & $56.35 * *$ & \\
\hline $\begin{array}{l}\text { FINAL ME* } \\
1,2 \text { e } 3\end{array}$ & 33.10 & 33.15 & 33.13 & 10.20 & 10.23 & 10.22 & 56.34 & 56.39 & 56.36 \\
\hline MÉDIA ME* & & 33.12 & & & 10.21 & & & 56.36 & \\
\hline
\end{tabular}

*ME - Mesa de Erickson.

**Medida prevista pelo programa Dolphin Imaging $11.9^{\circledR}$ após a movimentação da maxila. Azul - valores a serem encontrados de acordo com o Programa Dolphin Imaging 11.9 ${ }^{\circledR}$. Vermelho - valores encontrados na Mesa de Erickson.

Os resultados do Grupo 4 (linha média 3mm) explicitados na Tabela 10 acima demonstraram grande proximidade entre os resultados previstos pelo planejamento virtual 3D e os valores encontrados na Mesa de Erickson. Ocorreu exatidão no controle da medida transversa da LMS e a maior divergência encontrada foi de $0,05 \mathrm{~mm}$ na medida vertical (da LMS, elemento 16 e 26) assim como na medida horizontal do elemento 16. Na Tabela 11 a 
seguir (linha média $6 \mathrm{~mm}$ ) ocorreu exatidão no valor da medida horizontal do elemento 16 e a maior diferença foi de $0,06 \mathrm{~mm}$ (observada nas medidas horizontal e transversa da LMS).

Tabela 11 - Resultados Grupo 4 - LINHA MÉDIA (6mm)

\begin{tabular}{|c|c|c|c|c|c|c|c|c|c|}
\hline \multirow{2}{*}{$\begin{array}{l}\text { MOVIMENTAÇÃO } \\
\text { DA MAXILA: } \\
\text { MEDIDA } \\
\text { VERTICAL }\end{array}$} & \multicolumn{9}{|c|}{ Grupo 4 - LINHA MÉDIA 6MM } \\
\hline & & LMS & & & 16 & & & 26 & \\
\hline $\begin{array}{l}\text { INICIAL ME* } \\
1,2 \text { e } 3\end{array}$ & 92.21 & 92.19 & 92.17 & 93.70 & 93.65 & 93.64 & 97.33 & 97.27 & 97.25 \\
\hline INICIAL (MÉDIA) & & 92.19 & & & 93.66 & & & 97.28 & \\
\hline FINAL DOLPHIN & & 92.19 & & & 93.66 & & & 97.28 & \\
\hline $\begin{array}{l}\text { FINAL ME* } \\
1,2 \text { e } 3\end{array}$ & 92.26 & 92.23 & 92.25 & 93.68 & 93.70 & 93.71 & 97.34 & 97.31 & 97.29 \\
\hline MÉDIA ME* & & 92.24 & & & 93.69 & & & 97.31 & \\
\hline
\end{tabular}

\begin{tabular}{|c|c|c|c|c|c|c|c|c|c|}
\hline $\begin{array}{l}\text { MEDIDA } \\
\text { HORIZONTAL }\end{array}$ & & LMS & & & 16 & & & 26 & \\
\hline $\begin{array}{l}\text { INICIAL ME* } \\
1,2 \text { e } 3\end{array}$ & 54.80 & 54.86 & 54.84 & 25.29 & 25.32 & 25.30 & 24.45 & 24.49 & 24.48 \\
\hline INICIAL (MÉDIA) & & 54.83 & & & 25.30 & & & 24.47 & \\
\hline FINAL DOLPHIN & & 54.83 & & & 25.30 & & & 24.47 & \\
\hline $\begin{array}{l}\text { FINAL ME* } \\
1,2 \text { e } 3\end{array}$ & 54.90 & 54.88 & 54.91 & 25.33 & 25.28 & 25.29 & 24.52 & 24.50 & 24.49 \\
\hline MÉDIA ME* & & 54.89 & & & 25.30 & & & 24.50 & \\
\hline
\end{tabular}

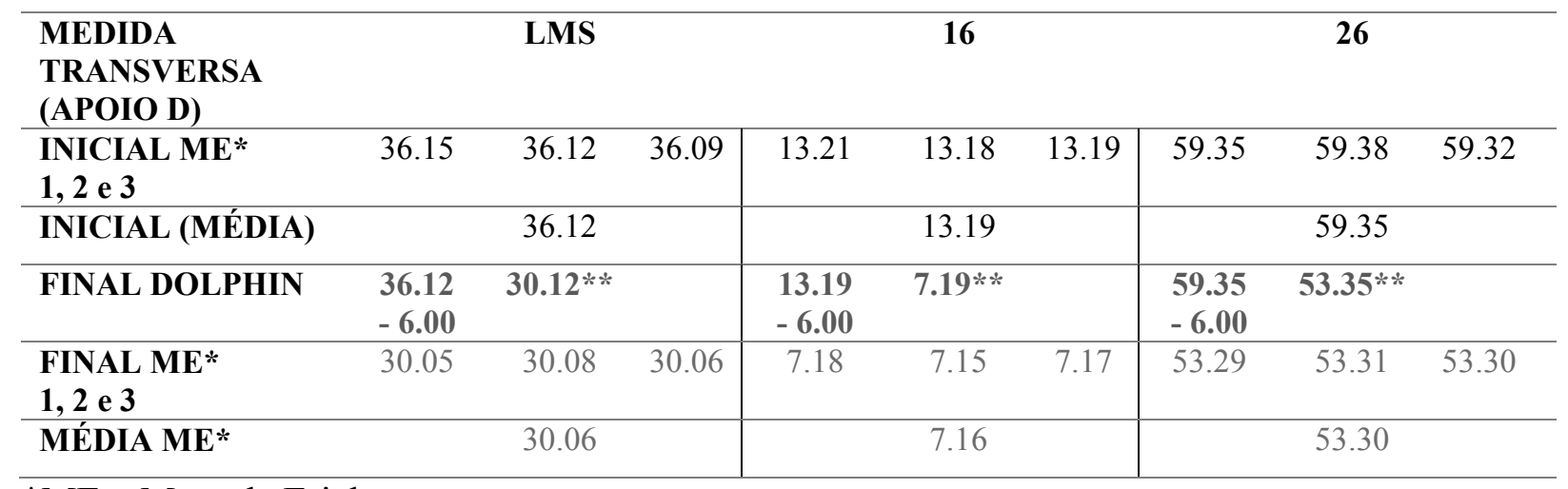

*ME - Mesa de Erickson.

**Medida prevista pelo programa Dolphin Imaging $11.9^{\circledR}$ após a movimentação da maxila. Azul - valores a serem encontrados de acordo com o Programa Dolphin Imaging 11.9 ${ }^{\circledR}$. Vermelho - valores encontrados na Mesa de Erickson. 
Nas Tabelas 12 e 13 observa-se os resultados obtidos pelo pesquisador para o Grupo 5 - REPOSICIONAMENTO INFERIOR INCISIVOS (3 e 6mm).

Tabela 12 - Resultados Grupo 5 - REPOSICIONAMENTO INFERIOR INCISIVOS (3mm) MOVIMENTAÇÃO Grupo 5 - REPOSICIONAMENTO INFERIOR INCISIVOS 3MM DA MAXILA:

\begin{tabular}{|c|c|c|c|c|c|c|c|c|c|}
\hline MEDIDA & \multicolumn{3}{|c|}{ LMS } & \multicolumn{3}{|c|}{16} & \multicolumn{3}{|c|}{26} \\
\hline $\begin{array}{l}\text { INICIAL ME* } \\
1,2 \text { e } 3\end{array}$ & 91.01 & 91.05 & 91.03 & 101.13 & 101.15 & 101.15 & 97.71 & 97.68 & 97.73 \\
\hline INICIAL (MÉDIA) & & 91.03 & & & 101.14 & & & 97.70 & \\
\hline FINAL DOLPHIN & $\begin{array}{r}91.03 \\
+3.00\end{array}$ & $94.03 * *$ & & $\begin{array}{c}101.14 \\
+0.70\end{array}$ & $101.84 * *$ & & $\begin{array}{r}\mathbf{9 7 . 7 0} \\
+0.35\end{array}$ & $98.05 * *$ & \\
\hline $\begin{array}{l}\text { FINAL ME* } \\
1,2 \text { e } 3\end{array}$ & 94.05 & 94.03 & 94.04 & 101.79 & 101.80 & 101.80 & 98.01 & 97.99 & 98.07 \\
\hline MÉDIA ME* & & 94.04 & & & 101.79 & & & 98.02 & \\
\hline
\end{tabular}

\begin{tabular}{|c|c|c|c|c|c|c|c|c|c|}
\hline $\begin{array}{l}\text { MEDIDA } \\
\text { HORIZONTAL }\end{array}$ & & LMS & & & 16 & & & 26 & \\
\hline $\begin{array}{l}\text { INICIAL ME* } \\
1,2 \text { e } 3\end{array}$ & 56.42 & 56.40 & 56.39 & 26.99 & 26.97 & 26.94 & 25.15 & 25.16 & 25.18 \\
\hline INICIAL (MÉDIA) & & 56.40 & & & 26.96 & & & 25.16 & \\
\hline FINAL DOLPHIN & & 56.40 & & $\begin{array}{r}26.96 \\
+0.38 \\
\end{array}$ & $27.34 * *$ & & $\begin{array}{r}25.16 \\
+0.56 \\
\end{array}$ & $25.72 * *$ & \\
\hline $\begin{array}{l}\text { FINAL ME* } \\
1,2 \text { e } 3\end{array}$ & 56.35 & 56.30 & 56.38 & 27.52 & 27.49 & 27.55 & 25.80 & 25.84 & 25.83 \\
\hline MÉDIA ME* & & 56.34 & & & 27.52 & & & 25.82 & \\
\hline
\end{tabular}

\begin{tabular}{|c|c|c|c|c|c|c|c|c|c|}
\hline $\begin{array}{l}\text { MEDIDA } \\
\text { TRANSVERSA } \\
\text { (APOIO D) }\end{array}$ & & LMS & & & 16 & & \multicolumn{3}{|c|}{26} \\
\hline $\begin{array}{l}\text { INICIAL ME* } \\
1,2 \text { e } 3\end{array}$ & 46.06 & 46.05 & 46.08 & 19.55 & 19.53 & 19.51 & 71.37 & 71.36 & 71.36 \\
\hline INICIAL (MÉDIA) & & 46.06 & & & 19.53 & & & 71.36 & \\
\hline FINAL DOLPHIN & & 46.06 & & & 19.53 & & & 71.36 & \\
\hline $\begin{array}{l}\text { FINAL ME* } \\
1,2 \text { e } 3\end{array}$ & 45.97 & 46.02 & 46.02 & 19.43 & 19.48 & 19.46 & 71.33 & 71.32 & 71.30 \\
\hline MÉDIA ME* & & 46.00 & & & 19.45 & & & 71.31 & \\
\hline
\end{tabular}

*ME - Mesa de Erickson.

**Medida prevista pelo programa Dolphin Imaging $11.9^{\circledR}$ após a movimentação da maxila.

Azul - valores a serem encontrados de acordo com o Programa Dolphin Imaging 11.9 ${ }^{\circledR}$.

Vermelho - valores encontrados na Mesa de Erickson. 
Os resultados do Grupo 5 (reposicionamento inferior de incisivos 3 e 6mm) observados nas Tabelas 12 e 13 não apresentaram exatidão entre o valor previsto no planejamento virtual 3D e a Mesa de Erickson em nenhuma medida. A maior diferença encontrada foi de $0,18 \mathrm{~mm}$ (ver Tabela 12 - medida horizontal do elemento 16; e Tabela 13 - medida transversa do elemento 16).

Tabela 13 - Resultados Grupo 5 - REPOSICIONAMENTO INFERIOR INCISIVOS (6mm)

\begin{tabular}{|c|c|c|c|c|c|c|c|c|c|}
\hline $\begin{array}{l}\text { MOVIMENTAÇÃO } \\
\text { DA MAXILA: }\end{array}$ & \multicolumn{9}{|c|}{ Grupo 5 - REPOSICIONAMENTO INFERIOR INCISIVOS 6MM } \\
\hline MEDIDA & & LMS & & & 16 & & & 26 & \\
\hline $\begin{array}{l}\text { INICIAL ME* } \\
1,2 \text { e } 3\end{array}$ & 91.01 & 91.05 & 91.03 & 101.13 & 101.15 & 101.15 & 97.71 & 97.68 & 97.73 \\
\hline INICIAL (MÉDIA) & & 91.03 & & & 101.14 & & & 97.70 & \\
\hline FINAL DOLPHIN & $\begin{array}{r}91.03 \\
+6.00\end{array}$ & $97.03 * *$ & & $\begin{array}{c}101.14 \\
+1.53\end{array}$ & $102.67 * *$ & & $\begin{array}{l}\mathbf{9 7 . 7 0} \\
+0.87\end{array}$ & $98.57 * *$ & \\
\hline $\begin{array}{l}\text { FINAL ME* } \\
1,2 \text { e } 3\end{array}$ & 97.08 & 97.10 & 97.12 & 102.59 & 102.63 & 102.63 & 98.58 & 98.55 & 98.57 \\
\hline MÉDIA ME* & & 97.10 & & & 102.61 & & & 98.56 & \\
\hline $\begin{array}{l}\text { MEDIDA } \\
\text { HORIZONTAL }\end{array}$ & & LMS & & & 16 & & & 26 & \\
\hline $\begin{array}{l}\text { INICIAL ME* } \\
1,2 \text { e } 3\end{array}$ & 56.42 & 56.40 & 56.39 & 26.99 & 26.97 & 26.94 & 25.15 & 25.16 & 25.18 \\
\hline INICIAL (MÉDIA) & & 56.40 & & & 26.96 & & & 25.16 & \\
\hline FINAL DOLPHIN & & 56.40 & & $\begin{array}{l}26.96 \\
+0.92\end{array}$ & $27.88 * *$ & & $\begin{array}{l}25.16 \\
+1.31\end{array}$ & $26.47 * *$ & \\
\hline $\begin{array}{l}\text { FINAL ME* } \\
1,2 \text { e } 3\end{array}$ & 56.43 & 56.45 & 56.39 & 27.95 & 27.92 & 27.94 & 26.46 & 26.44 & 26.45 \\
\hline MÉDIA ME* & & 56.42 & & & 27.93 & & & 26.45 & \\
\hline $\begin{array}{l}\text { MEDIDA } \\
\text { TRANSVERSA } \\
\text { (APOIO D) }\end{array}$ & & LMS & & & 16 & & & 26 & \\
\hline $\begin{array}{l}\text { INICIAL ME* } \\
1,2 \text { e } 3\end{array}$ & 46.06 & 46.05 & 46.08 & 19.55 & 19.53 & 19.51 & 71.37 & 71.36 & 71.36 \\
\hline INICIAL (MÉDIA) & & 46.06 & & & 19.53 & & & 71.36 & \\
\hline FINAL DOLPHIN & & 46.06 & & & 19.53 & & & 71.36 & \\
\hline $\begin{array}{l}\text { FINAL ME* } \\
1,2 \text { e } 3\end{array}$ & 46.12 & 46.09 & 46.09 & 19.33 & 19.38 & 19.36 & 71.30 & 71.28 & 71.32 \\
\hline MÉDIA ME* & & 46.10 & & & 19.35 & & & 71.30 & \\
\hline
\end{tabular}

*ME - Mesa de Erickson.

** Medida prevista pelo programa Dolphin Imaging $11.9^{\circledR}$ após a movimentação da maxila.

Azul - valores a serem encontrados de acordo com o Programa Dolphin Imaging 11.9 ${ }^{\circledR}$.

Vermelho - valores encontrados na Mesa de Erickson. 
Os resultados do Grupo 6 - REPOSICIONAMENTO INFERIOR MOLARES (3 e 6mm) são observados a seguir nas Tabelas 14 e 15.

Tabela 14 - Resultados Grupo 6 - REPOSICIONAMENTO INFERIOR MOLARES (3mm)

MOVIMENTAÇÃO Grupo 6 - REPOSICIONAMENTO INFERIOR MOLARES 3MM
DA MAXILA:

\begin{tabular}{|c|c|c|c|c|c|c|c|c|c|}
\hline MEDIDA & & LMS & & & 16 & & & 26 & \\
\hline $\begin{array}{l}\text { INICIAL ME* } \\
1,2 \text { e } 3\end{array}$ & 88.10 & 88.13 & 88.11 & 94.73 & 94.76 & 94.77 & 93.91 & 93.90 & 93.93 \\
\hline INICIAL (MÉDIA) & & 88.11 & & & 94.75 & & & 93.91 & \\
\hline FINAL DOLPHIN & & 88.11 & & $\begin{array}{r}94.75 \\
+3.00\end{array}$ & $97.75 * *$ & & $\begin{array}{r}93.91 \\
+3.08\end{array}$ & $96.99 * *$ & \\
\hline $\begin{array}{l}\text { FINAL ME* } \\
1,2 \text { e } 3\end{array}$ & 88.03 & 88.07 & 88.10 & 97.62 & 97.59 & 97.64 & 96.82 & 96.80 & 96.77 \\
\hline MÉDIA ME* & & 88.06 & & & 97.61 & & & 96.79 & \\
\hline $\begin{array}{l}\text { MEDIDA } \\
\text { HORIZONTAL }\end{array}$ & & LMS & & & 16 & & & 26 & \\
\hline $\begin{array}{l}\text { INICIAL ME* } \\
1,2 \text { e } 3\end{array}$ & 50.34 & 50.36 & 50.37 & 21.90 & 21.92 & 21.93 & 20.70 & 20.69 & 20.67 \\
\hline INICIAL (MÉDIA) & & 50.35 & & & 21.91 & & & 20.68 & \\
\hline FINAL DOLPHIN & & 50.35 & & $\begin{array}{l}21.91 \\
-0.17\end{array}$ & $21.74 * *$ & & $\begin{array}{r}20.68 \\
-0.05\end{array}$ & $20.63 * *$ & \\
\hline $\begin{array}{l}\text { FINAL ME* } \\
1,2 \text { e } 3\end{array}$ & 50.39 & 50.37 & 50.37 & 21.62 & 21.65 & 21.67 & 20.68 & 20.66 & 20.66 \\
\hline MÉDIA ME* & & 50.37 & & & 21.64 & & & 20.66 & \\
\hline $\begin{array}{l}\text { MEDIDA } \\
\text { TRANSVERSA } \\
\text { (APOIO D) }\end{array}$ & & LMS & & & 16 & & & 26 & \\
\hline $\begin{array}{l}\text { INICIAL ME* } \\
1,2 \text { e } 3\end{array}$ & 43.34 & 43.32 & 43.31 & 17.65 & 17.68 & 17.69 & 68.12 & 68.09 & 68.08 \\
\hline INICIAL (MÉDIA) & & 43.32 & & & 17.67 & & & 68.09 & \\
\hline FINAL DOLPHIN & & 43.32 & & & 17.67 & & & 68.09 & \\
\hline $\begin{array}{l}\text { FINAL ME* } \\
1,2 \text { e } 3\end{array}$ & 43.00 & 43.02 & 42.95 & 17.42 & 17.32 & 17.40 & 68.43 & 68.35 & 68.38 \\
\hline MÉDIA ME* & & 42.99 & & & 17.38 & & & 68.38 & \\
\hline
\end{tabular}

*ME - Mesa de Erickson.

**Medida prevista pelo programa Dolphin Imaging $11.9^{\circledR}$ após a movimentação da maxila.

Azul - valores a serem encontrados de acordo com o Programa Dolphin Imaging 11.9 ${ }^{\circledR}$.

Vermelho - valores encontrados na Mesa de Erickson.

$\mathrm{Na}$ Tabela 14 observa-se que os resultados encontrados para o Grupo 6 (reposicionamento inferior de molares em $3 \mathrm{~mm}$ ) indicam maiores divergências na medida 
transversa: 0,29mm nas medidas dos elementos 16 e 26; 0,33m na medida da LMS. Já na Tabela 15 a seguir, o Grupo 6 (reposicionamento inferior de molares em $6 \mathrm{~mm}$ ) apresentou maiores diferenças na medida vertical do elemento $16(0,30 \mathrm{~mm})$ e transversa do elemento $26(0,26 \mathrm{~mm})$.

Tabela 15 - Resultados Grupo 6 - REPOSICIONAMENTO INFERIOR MOLARES (6mm)

\begin{tabular}{|c|c|c|c|c|c|c|c|c|c|}
\hline MOVIMENTAÇÃO & \multicolumn{9}{|c|}{ Grupo 6 - REPOSICIONAMENTO INFERIOR MOLARES 6MM } \\
\hline $\begin{array}{l}\text { MEDIDA } \\
\text { VERTICAL } \\
\end{array}$ & & LMS & & & 16 & & & 26 & \\
\hline $\begin{array}{l}\text { INICIAL ME* } \\
1,2 \text { e } 3\end{array}$ & 88.10 & 88.13 & 88.11 & 94.73 & 94.76 & 94.77 & 93.91 & 93.90 & 93.93 \\
\hline INICIAL (MÉDIA) & & 88.11 & & & 94.75 & & & 93.91 & \\
\hline FINAL DOLPHIN & & 88.11 & & $\begin{array}{r}94.75 \\
+6.00\end{array}$ & $100.75 * *$ & & $\begin{array}{r}93.91 \\
+6.14 \\
\end{array}$ & $100.05 * *$ & \\
\hline $\begin{array}{l}\text { FINAL ME* } \\
1,2 \text { e } 3\end{array}$ & 88.08 & 88.05 & 88.04 & 100.43 & 100.48 & 100.46 & 99.84 & 99.81 & 99.86 \\
\hline MÉDIA ME* & & 88.05 & & & 100.45 & & & 99.83 & \\
\hline $\begin{array}{l}\text { MEDIDA } \\
\text { HORIZONTAL }\end{array}$ & & LMS & & & 16 & & & 26 & \\
\hline $\begin{array}{l}\text { INICIAL ME* } \\
1,2 \text { e } 3\end{array}$ & 50.34 & 50.36 & 50.37 & 21.90 & 21.92 & 21.93 & 20.70 & 20.69 & 20.67 \\
\hline INICIAL (MÉDIA) & & 50.35 & & & 21.91 & & & 20.68 & \\
\hline FINAL DOLPHIN & & 50.35 & & & 21.91 & & $\begin{array}{r}20.68 \\
+0.23 \\
\end{array}$ & $20.91 * *$ & \\
\hline $\begin{array}{l}\text { FINAL ME* } \\
1,2 \text { e } 3\end{array}$ & 50.27 & 50.31 & 50.30 & 21.89 & 21.87 & 21.86 & 20.84 & 20.82 & 20.82 \\
\hline MÉDIA ME* & & 50.29 & & & 21.87 & & & 20.82 & \\
\hline $\begin{array}{l}\text { MEDIDA } \\
\text { TRANSVERSA } \\
\text { (APOIO D) }\end{array}$ & & LMS & & & 16 & & & 26 & \\
\hline $\begin{array}{l}\text { INICIAL ME* } \\
1,2 \text { e } 3\end{array}$ & 43.34 & 43.32 & 43.31 & 17.65 & 17.68 & 17.69 & 68.12 & 68.09 & 68.08 \\
\hline INICIAL (MÉDIA) & & 43.32 & & & 17.67 & & & 68.09 & \\
\hline FINAL DOLPHIN & & 43.32 & & & 17.67 & & & 68.09 & \\
\hline $\begin{array}{l}\text { FINAL ME* } \\
1,2 \text { e } 3\end{array}$ & 43.22 & 43.23 & 43.25 & 17.41 & 17.43 & 17.44 & 68.38 & 68.35 & 68.32 \\
\hline MÉDIA ME* & & 43.23 & & & 17.42 & & & 68.35 & \\
\hline
\end{tabular}

*ME - Mesa de Erickson.

**Medida prevista pelo programa Dolphin Imaging $11.9^{\circledR}$ após a movimentação da maxila.

Azul - valores a serem encontrados de acordo com o Programa Dolphin Imaging $11.9^{\circledR}$.

Vermelho - valores encontrados na Mesa de Erickson. 
Nas Tabelas 16 e 17 observa-se os resultados dos Grupos 7 e 8.

Tabela 16 - Resultados Grupo 7 - AVANÇO + RS INCISIVOS + RI MOLARES

MOVIMENTAÇÃO Grupo 7 - AVANÇO + RS INCISIVOS + RI MOLARES
DA MAXILA:

\begin{tabular}{|c|c|c|c|c|c|c|c|c|c|}
\hline $\begin{array}{l}\text { MEDIDA } \\
\text { VERTICAL }\end{array}$ & & LMS & & & 16 & & & 26 & \\
\hline $\begin{array}{l}\text { INICIAL ME* } \\
1,2 \text { e } 3\end{array}$ & 110.14 & 110.17 & 110.17 & 116.52 & 116.55 & 116.54 & 116.35 & 116.35 & 116.32 \\
\hline INICIAL (MÉDIA) & & 110.16 & & & 116.53 & & & 116.34 & \\
\hline FINAL DOLPHIN & $\begin{array}{l}110.16 \\
-3.00\end{array}$ & $107.16 * *$ & & $\begin{array}{r}116.53 \\
+3.27 \\
\end{array}$ & $119.80 * *$ & & $\begin{array}{l}116.34 \\
+3.00 \\
\end{array}$ & $119.34 * *$ & \\
\hline $\begin{array}{l}\text { FINAL ME* } \\
1,2 \text { e } 3\end{array}$ & 106.99 & 106.92 & 106.96 & 119.60 & 119.59 & 119.59 & 119.21 & 119.15 & 119.19 \\
\hline MÉDIA ME* & & 106.95 & & & 119.59 & & & 119.18 & \\
\hline
\end{tabular}

\begin{tabular}{|c|c|c|c|c|c|c|c|c|c|}
\hline $\begin{array}{l}\text { MEDIDA } \\
\text { HORIZONTAL }\end{array}$ & & LMS & & & 16 & & & 26 & \\
\hline $\begin{array}{l}\text { INICIAL ME* } \\
1,2 \text { e } 3\end{array}$ & 68.65 & 68.63 & 68.66 & 34.84 & 34.86 & 34.86 & 36.54 & 36.55 & 36.57 \\
\hline INICIAL (MÉDIA) & & 68.64 & & & 34.85 & & & 36.55 & \\
\hline FINAL DOLPHIN & $\begin{array}{r}68.64 \\
+6.00\end{array}$ & $74.64 * *$ & & $\begin{array}{r}34.85 \\
+7.54\end{array}$ & $42.39 * *$ & & $\begin{array}{r}36.55 \\
+7.19\end{array}$ & $43.74 * *$ & \\
\hline $\begin{array}{l}\text { FINAL ME* } \\
1,2 \text { e } 3\end{array}$ & 74.43 & 74.41 & 74.46 & 42.30 & 42.30 & 42.32 & 43.66 & 43.69 & 43.69 \\
\hline MÉDIA ME* & & 74.43 & & & 42.30 & & & 43.68 & \\
\hline
\end{tabular}

\begin{tabular}{|c|c|c|c|c|c|c|c|c|c|}
\hline $\begin{array}{l}\text { MEDIDA } \\
\text { TRANSVERSA } \\
\text { (APOIO D) }\end{array}$ & & LMS & & & 16 & & & 26 & \\
\hline $\begin{array}{l}\text { INICIAL ME* } \\
1,2 \text { e } 3\end{array}$ & 39.23 & 39.23 & 39.25 & 11.54 & 11.57 & 11.56 & 67.22 & 67.19 & 67.19 \\
\hline INICIAL (MÉDIA) & & 39.23 & & & 11.55 & & & 67.20 & \\
\hline FINAL DOLPHIN & & 39.23 & & & 11.55 & & & 67.20 & \\
\hline $\begin{array}{l}\text { FINAL ME* } \\
1,2 \text { e } 3\end{array}$ & 39.20 & 39.23 & 39.20 & 11.61 & 11.57 & 11.58 & 67.18 & 67.21 & 67.20 \\
\hline MÉDIA ME* & & 39.21 & & & 11.58 & & & 67.19 & \\
\hline
\end{tabular}

*ME - Mesa de Erickson.

**Medida prevista pelo programa Dolphin Imaging $11.9^{\circledR}$ após a movimentação da maxila.

Azul - valores a serem encontrados de acordo com o Programa Dolphin Imaging 11.9 ${ }^{\circledR}$.

Vermelho - valores encontrados na Mesa de Erickson. 
O Grupo 7 (avanço + RS incisivos + RI molares) apresentou proximidade entre os resultados do planejamento virtual 3D e da Mesa de Erickson, e a maior diferença foi encontrada nas medidas horizontal e vertical da LMS e também na medida vertical do elemento 16: 0,21 mm. Já na Tabela 17 a seguir, o Grupo 8 (avanço + RI incisivos + RS molares) a maior divergência de valores encontrada foi de $0,12 \mathrm{~mm}$, na medida vertical do elemento 26 .

Tabela 17 - Resultados Grupo 8 - AVANÇO + RI INCISIVOS + RS MOLARES

\begin{tabular}{|c|c|c|c|c|c|c|c|c|c|}
\hline \multirow{2}{*}{$\begin{array}{l}\text { MOVIMENTAÇÃO } \\
\text { DA MAXILA: } \\
\text { MEDIDA } \\
\text { VERTICAL }\end{array}$} & \multicolumn{9}{|c|}{ Grupo 8 - AVANÇO + RI INCISIVOS + RS MOLARES } \\
\hline & & LMS & & & 16 & & & 26 & \\
\hline $\begin{array}{l}\text { INICIAL ME* } \\
1,2 \text { e } 3\end{array}$ & 101.50 & 101.54 & 101.55 & 102.08 & 102.02 & 101.98 & 100.88 & 100.92 & 100.91 \\
\hline INICIAL (MÉDIA) & & 101.53 & & & 102.02 & & & 100.90 & \\
\hline FINAL DOLPHIN & $\begin{array}{l}101.53 \\
+3.00\end{array}$ & $104.53 * *$ & & $\begin{array}{l}102.02 \\
-3.25\end{array}$ & $98.77 * *$ & & $\begin{array}{l}100.90 \\
-3.00\end{array}$ & $97.90 * *$ & \\
\hline $\begin{array}{l}\text { FINAL ME* } \\
1,2 \text { e } 3\end{array}$ & 104.51 & 104.55 & 104.56 & 98.84 & 98.81 & 98.82 & 98.02 & 97.99 & 98.05 \\
\hline MÉDIA ME* & & 104.54 & & & 98.82 & & & 98.02 & \\
\hline $\begin{array}{l}\text { MEDIDA } \\
\text { HORIZONTAL }\end{array}$ & & LMS & & & 16 & & & 26 & \\
\hline $\begin{array}{l}\text { INICIAL ME* } \\
1,2 \text { e } 3\end{array}$ & 74.55 & 74.51 & 74.51 & 40.35 & 40.31 & 40.33 & 41.50 & 41.55 & 41.48 \\
\hline INICIAL (MÉDIA) & & 74.52 & & & 40.33 & & & 41.51 & \\
\hline FINAL DOLPHIN & $\begin{array}{r}74.52 \\
+6.00 \\
\end{array}$ & $80.52 * *$ & & $\begin{array}{r}40.33 \\
+7.54 \\
\end{array}$ & $47.87 * *$ & & $\begin{array}{r}41.51 \\
+7.54\end{array}$ & $49.05 * *$ & \\
\hline $\begin{array}{l}\text { FINAL ME* } \\
1,2 \text { e } 3\end{array}$ & 80.49 & 80.53 & 80.52 & 47.89 & 47.86 & 47.85 & 49.10 & 49.08 & 49.12 \\
\hline MÉDIA ME* & & 80.51 & & & 47.86 & & & 49.10 & \\
\hline $\begin{array}{l}\text { MEDIDA } \\
\text { TRANSVERSA } \\
\text { (APOIO D) }\end{array}$ & & LMS & & & 16 & & & 26 & \\
\hline $\begin{array}{l}\text { INICIAL ME* } \\
1,2 \text { e } 3\end{array}$ & 40.37 & 40.39 & 40.40 & 15.06 & 15.09 & 15.12 & 66.40 & 66.43 & 66.43 \\
\hline INICIAL (MÉDIA) & & 40.38 & & & 15.09 & & & 66.42 & \\
\hline FINAL DOLPHIN & & 40.38 & & & 15.09 & & & 66.42 & \\
\hline $\begin{array}{l}\text { FINAL ME* } \\
1,2 \text { e } 3\end{array}$ & 40.44 & 40.41 & 40.46 & 15.08 & 15.13 & 15.13 & 66.43 & 66.46 & 66.47 \\
\hline MÉDIA ME* & & 40.43 & & & 15.11 & & & 66.45 & \\
\hline
\end{tabular}

*ME - Mesa de Erickson.

**Medida prevista pelo programa Dolphin Imaging $11.9^{\circledR}$ após a movimentação da maxila.

Azul - valores a serem encontrados de acordo com o Programa Dolphin Imaging $11.9^{\circledR}$.

Vermelho - valores encontrados na Mesa de Erickson. 
Os dados obtidos foram tabulados e submetidos à análise estatística. Realizou-se estatística descritiva (ver Tabelas 18 e 19).

Tabela 18 - Análise descritiva dos dados.

\begin{tabular}{|c|c|c|c|c|c|c|c|c|}
\hline Local & Movimento & Variável & $\mathbf{n}$ & Média & $\begin{array}{l}\text { Desvio- } \\
\text { padrão }\end{array}$ & Mínimo & Mediana & Máximo \\
\hline \multirow{4}{*}{16} & \multirow{2}{*}{3} & Dolphin & 54 & 48,80 & 37,68 & 10,18 & 27,47 & 110,75 \\
\hline & & ME* & 54 & 48,73 & 37,66 & 10,20 & 27,44 & 110,55 \\
\hline & \multirow{2}{*}{6} & Dolphin & 72 & 50,65 & 38,60 & 7,18 & 34,35 & 119,82 \\
\hline & & ME* & 72 & 50,57 & 38,55 & 7,15 & 34,39 & 119,60 \\
\hline \multirow{4}{*}{26} & \multirow{2}{*}{3} & Dolphin & 54 & 64,63 & 28,52 & 20,62 & 66,68 & 102,80 \\
\hline & & ME* & 54 & 64,57 & 28,48 & 20,66 & 66,69 & 102,48 \\
\hline & \multirow{2}{*}{6} & Dolphin & 72 & 67,02 & 28,18 & 20,90 & 66,68 & 119,35 \\
\hline & & ME* & 72 & 66,99 & 28,14 & 20,82 & 66,71 & 119,21 \\
\hline \multirow{4}{*}{ LMS } & \multirow{2}{*}{3} & Dolphin & 54 & 64,86 & 23,39 & 33,09 & 57,74 & 102,74 \\
\hline & & ME* & 54 & 64,82 & 23,42 & 33,10 & 57,70 & 102,71 \\
\hline & \multirow{2}{*}{6} & Dolphin & 72 & 67,25 & 24,95 & 30,09 & 64,53 & 107,17 \\
\hline & & ME* & 72 & 67,21 & 24,95 & 30,05 & 64,56 & 106,99 \\
\hline
\end{tabular}

*ME - Mesa de Erickson.

Na Tabela 18 acima, observa-se a amostra (n) de medidas encontradas de acordo com cada ponto de referência e quantidade de movimento (3 e $6 \mathrm{~mm}$ ), suas respectivas médias, desvio-padrão, valor mínimo, valor máximo e mediana. A maior média ocorreu na Linha Média Superior (LMS) na movimentação de $6 \mathrm{~mm}$ e a menor foi encontrada no elemento 16 (movimento de $3 \mathrm{~mm}$ ).

Tabela 19 - Análise descritiva da variação entre Dolphin Imaging $11.9^{\circledR}$ e Mesa de Erickson.

\begin{tabular}{cccccccc}
\hline \multirow{2}{*}{ Local } & \multirow{2}{*}{ Movimento } & \multicolumn{6}{c}{ Dolphin - Mesa de Erickson } \\
\cline { 2 - 8 } & $\mathbf{n}$ & Média & Desvio-padrão & Mínimo & Mediana & Máximo \\
\hline \multirow{2}{*}{$\mathbf{1 6}$} & $\mathbf{3}$ & 54 & 0,07 & 0,11 & $-0,23$ & 0,05 & 0,36 \\
& $\mathbf{6}$ & 72 & 0,07 & 0,13 & $-0,20$ & 0,04 & 0,42 \\
\hline \multirow{2}{*}{$\mathbf{2 6}$} & $\mathbf{3}$ & 54 & 0,05 & 0,15 & $-0,31$ & 0,03 & 0,39 \\
& $\mathbf{6}$ & 72 & 0,03 & 0,14 & $-0,26$ & 0,02 & 0,42 \\
\hline \multirow{2}{*}{ LMS } & $\mathbf{3}$ & 54 & 0,04 & 0,09 & $-0,13$ & 0,03 & 0,36 \\
& $\mathbf{6}$ & 72 & 0,04 & 0,09 & $-0,11$ & 0,04 & 0,25 \\
\hline
\end{tabular}

Observa-se na Tabela 19 acima, a pequena variação entre os valores previstos pelo Dolphin Imaging $11.9^{\circledR}$ e os valores encontrados na Mesa de Erickson. A maior variação 
encontrada foi de $0,42 \mathrm{~mm}$ e o desvio-padrão não ultrapassou o valor de 0,15 . A maior média foi de $0,07 \mathrm{~mm}$ e ocorreu no elemento 16 .

$\mathrm{Na}$ Tabela 20 a seguir, demonstra-se as comparações do delta em cada ponto de referência. Observa-se a ausência de diferenças estatisticamente significantes, pois os valores de p foram 0,67 para a LMS, 0,57 para o elemento 16 e 0,47 para o elemento 26.

Tabela 20 - Comparações do delta (Dolphin - Mesa de Erickson) entre os movimentos (3mm e $6 \mathrm{~mm})$ em cada ponto de referência.

\begin{tabular}{cccc}
\hline Local & Diferença estimada (3mm - 6 $\mathbf{m m})$ & Intervalo de confiança (95\%) & Valor-p \\
\hline LMS & 0,006 & $-0,024 ; 0,036$ & 0,67 \\
16 & $-0,012$ & $-0,052 ; 0,029$ & 0,57 \\
26 & 0,019 & $-0,032 ; 0,069$ & 0,47 \\
\hline
\end{tabular}

Foi avaliada a existência de concordância entre Dolphin Imaging $11.9^{\circledR}$ e Mesa de Erickson, como demonstram as Tabela 21 e 22 a seguir. Analisou-se a concordância quanto ao ponto de referência e quantidade de movimento (Tabela 21) e somente quanto ao ponto de referência separadamente (Tabela 22).

Observa-se uma concordância quase perfeita entre o Dolphin Imaging $11.9^{\circledR}$ e Mesa de Erickson, pois a menor concordância encontrada foi de 0,9887 (ver Tabela 22).

Tabela 21 - Coeficiente de correlação intraclasses de acordo com o ponto de referência e a quantidade de movimentação.

\begin{tabular}{cccc}
\hline Local & Movimento & CCI & IC (95\%) \\
\hline \multirow{2}{*}{ LMS } & $3 \mathrm{~mm}$ & 0,9999 & 0,$9997 ; 0,9999$ \\
& $6 \mathrm{~mm}$ & 0,9999 & 0,$9998 ; 1$ \\
\hline \multirow{2}{*}{16} & $3 \mathrm{~mm}$ & 0,9997 & 0,$9993 ; 0,9999$ \\
& $6 \mathrm{~mm}$ & 0,9998 & 0,$9996 ; 0,9999$ \\
\hline \multirow{2}{*}{26} & $3 \mathrm{~mm}$ & 0,9996 & 0,$999 ; 0,9998$ \\
& $6 \mathrm{~mm}$ & 0,9998 & 0,$9997 ; 0,9999$ \\
\hline
\end{tabular}

Tabela 22 - Coeficiente de correlação intraclasses de acordo com o ponto de referência.

\begin{tabular}{ccc}
\hline Local & CCI & IC (95\%) \\
\hline LMS & 0,9891 & 0,$9801 ; 0,9940$ \\
16 & 0,9887 & 0,$9802 ; 0,9936$ \\
26 & 0,9891 & 0,$9804 ; 0,9939$ \\
\hline
\end{tabular}


Para melhor visualização da concordância, as medidas foram representadas pelos gráficos de dispersão e pelos gráficos de Bland-Altman.

\section{LMS}

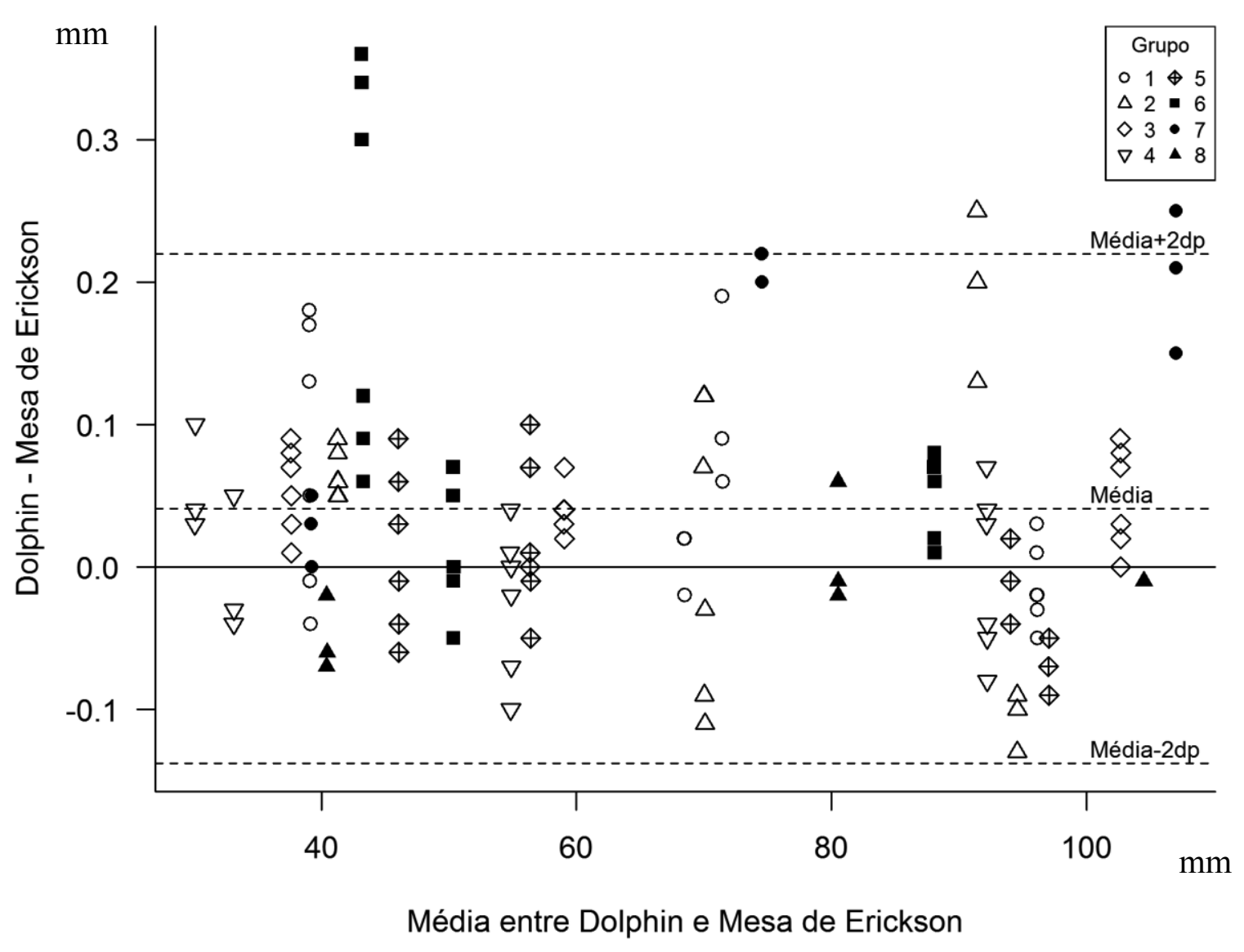

Figura 5 - Gráfico de Bland-Altman avaliando a variação da diferença entre as medidas do Dolphin Imaging $11.9^{\circledR}$ e Mesa de Erickson na Linha Média Superior (LMS). 
16

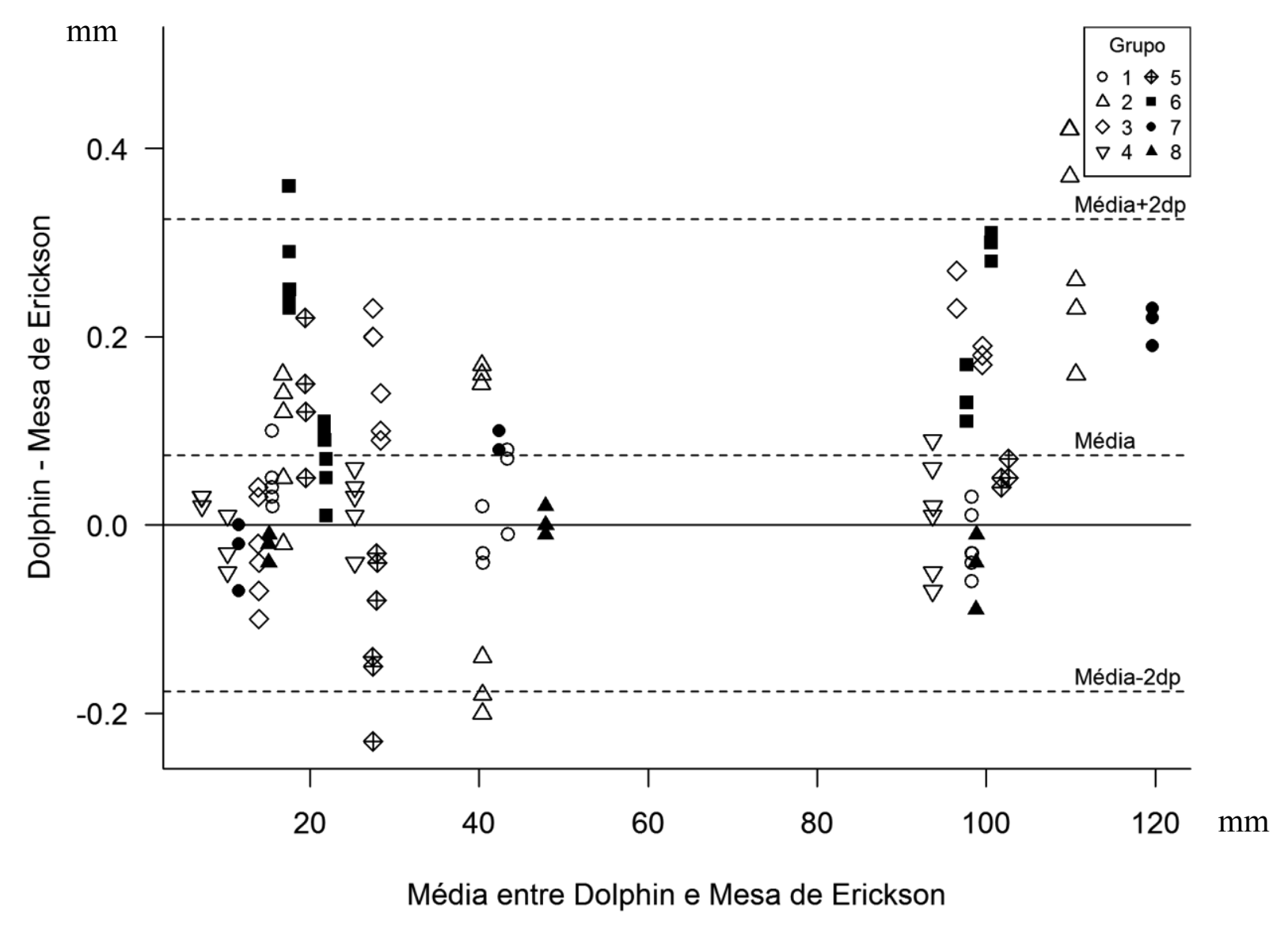

Figura 6 - Gráfico de Bland-Altman avaliando a variação da diferença entre as medidas do Dolphin Imaging $11.9^{\circledR}$ e Mesa de Erickson no elemento 16. 


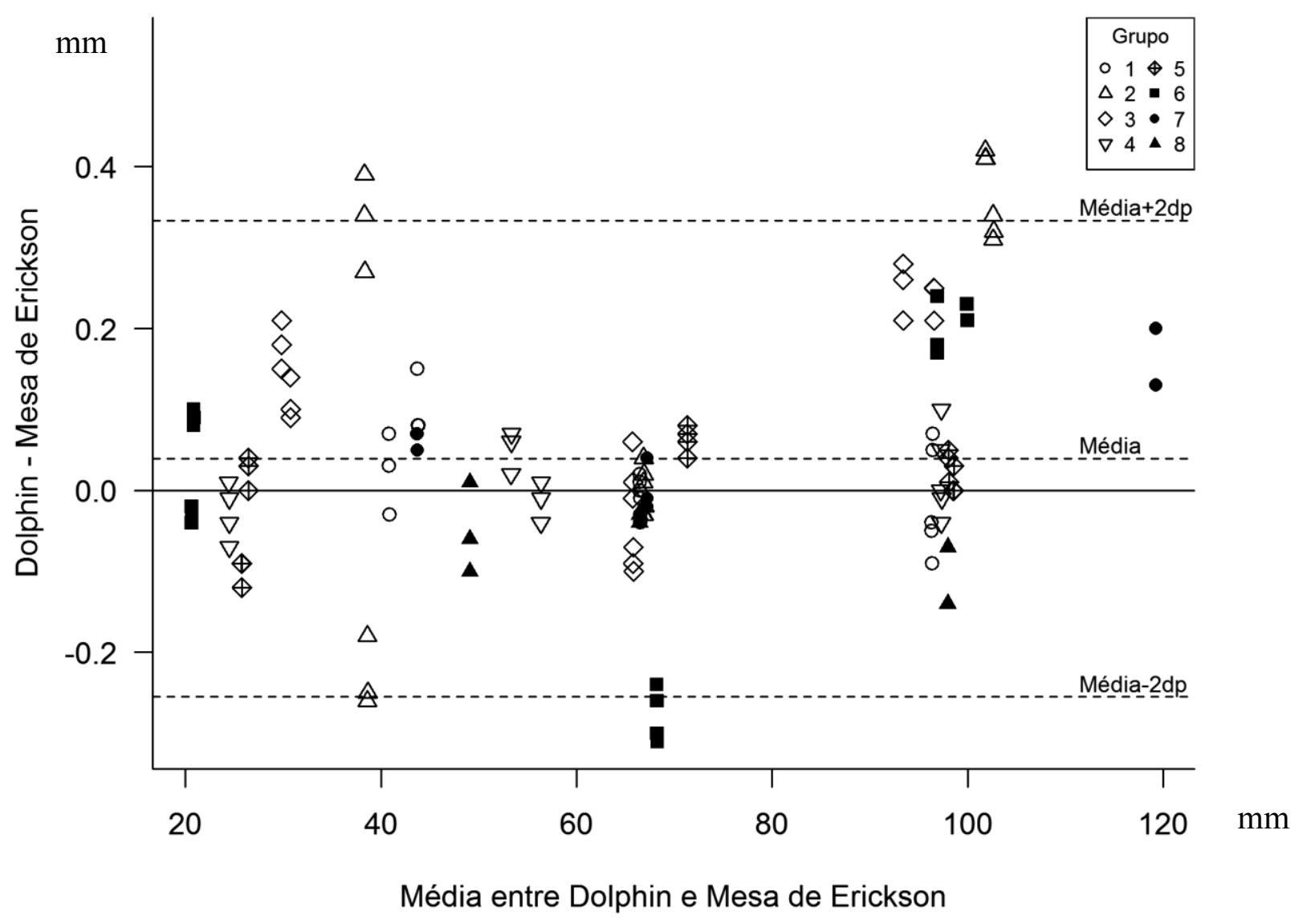

Figura 7 - Gráfico de Bland-Altman avaliando a variação da diferença entre as medidas do Dolphin Imaging $11.9^{\circledR}$ e Mesa de Erickson no elemento 26.

Observa-se nas Figuras 5, 6 e 7 acima que os gráficos elaborados de acordo com cada ponto de referência evidenciam os grupos estudados por meio de diferentes símbolos (ver legenda) e a maioria dos grupos aproxima-se do zero absoluto, independentemente do ponto de referência avaliado. Isso demonstra a excelente concordância encontrada.

As Figuras 8, 9 e 10 abaixo demonstram o Gráfico de Dispersão para cada ponto de referência. Observa-se que todas as medidas encontram-se na linha do gráfico que indica a concordância entre os métodos (Dolphin Imaging $11.9^{\circledR}$ e Mesa de Erickson). 


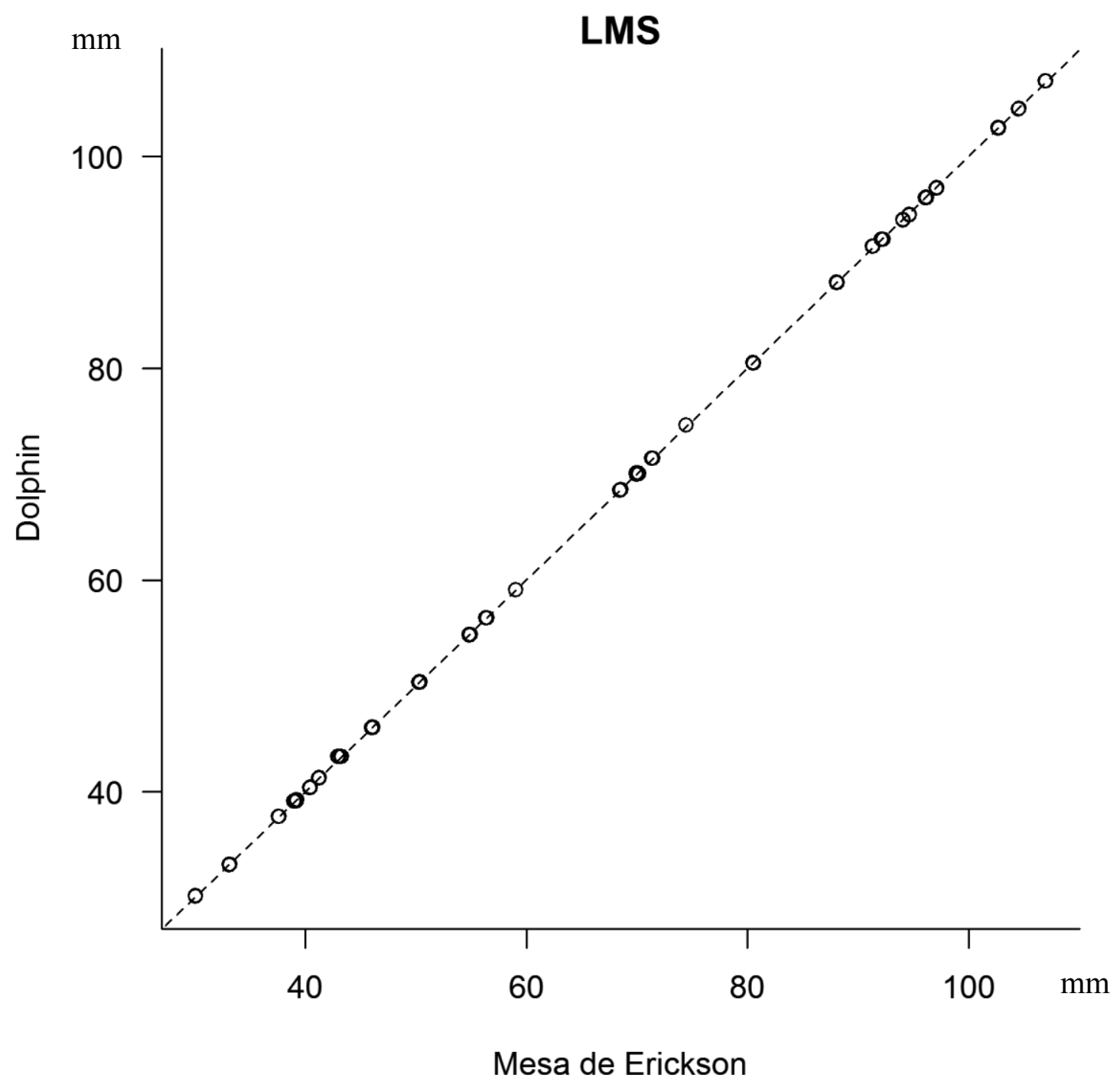

Figura 8 - Gráfico de Dispersão avaliando a concordância entre as medidas do Dolphin Imaging $11.9^{\circledR}$ e Mesa de Erickson na Linha Média Superior (LMS). 


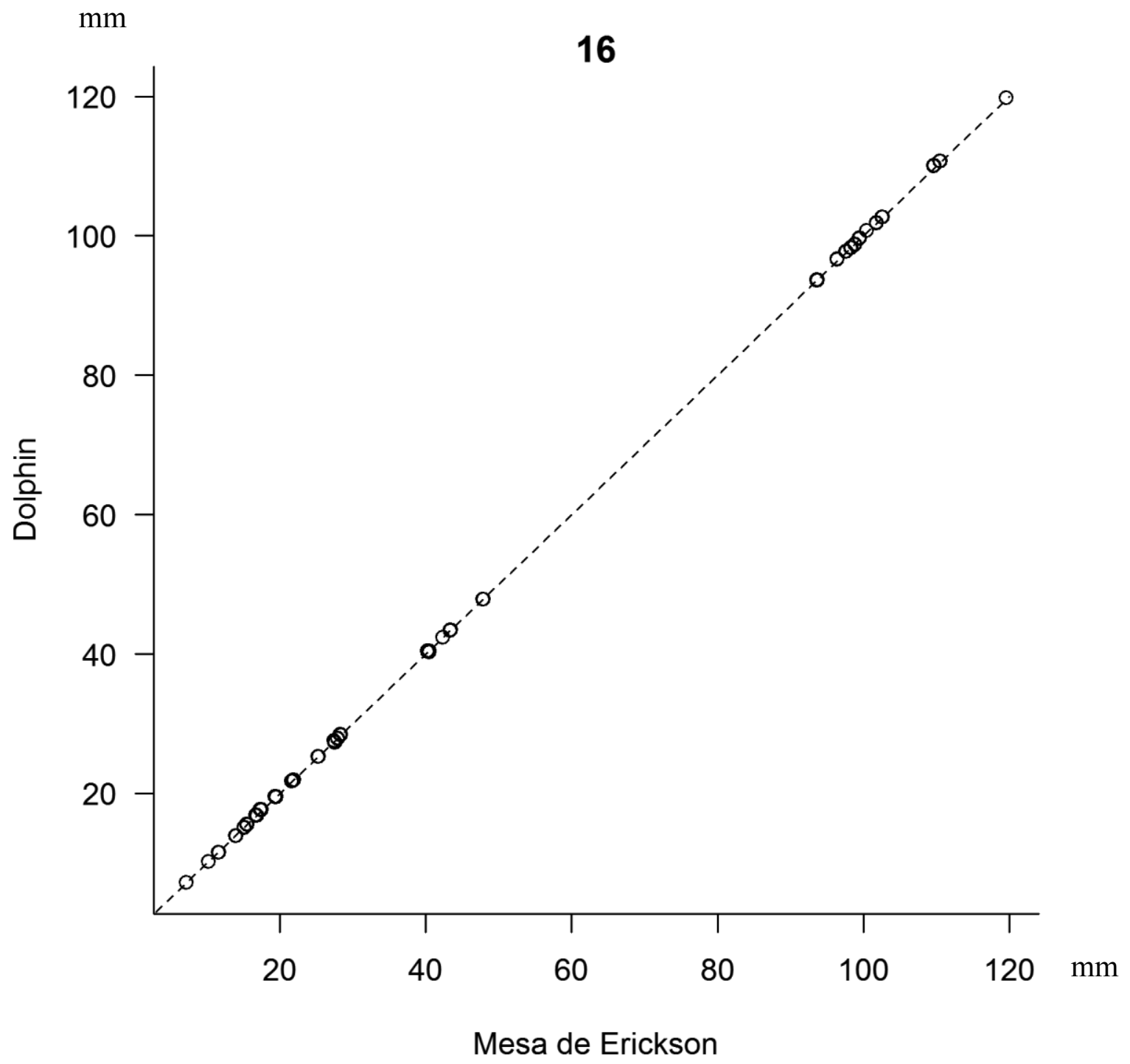

Figura 9 - Gráfico de Dispersão avaliando a concordância entre as medidas do Dolphin Imaging $11.9^{\circledR}$ e Mesa de Erickson no elemento 16. 


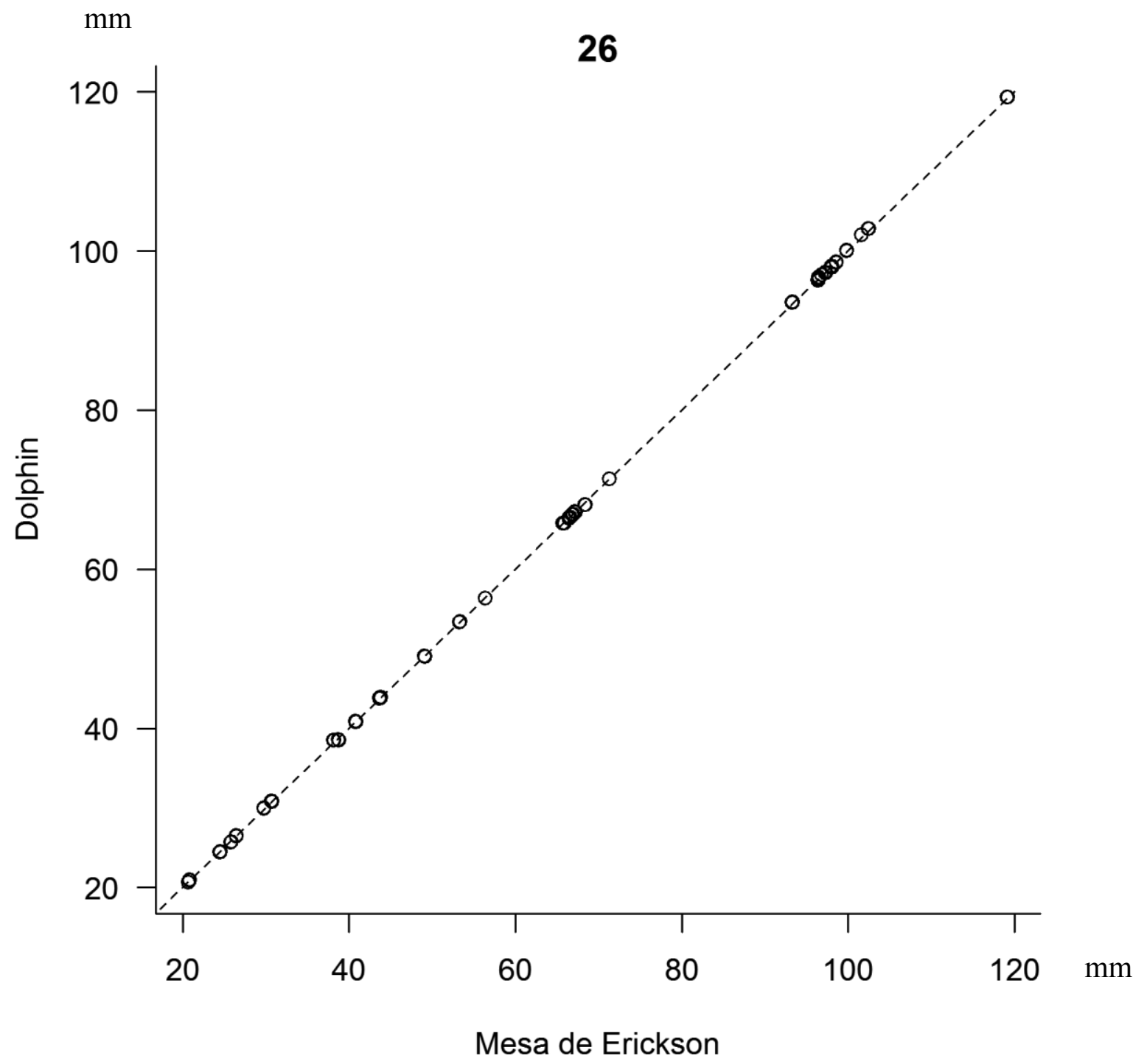

Figura 10 - Gráfico de Dispersão avaliando a concordância entre as medidas do Dolphin Imaging $11.9^{\circledR}$ e Mesa de Erickson no elemento 26. 


\section{DISCUSSÃO}

O planejamento virtual em cirurgia ortognática produz excelentes resultados funcionais e estéticos, satisfação do paciente, plano de tratamento preciso e facilitação da técnica intraoperatória (31).

São descritos na literatura diferentes métodos de comparação entre planejamento e resultados em cirurgia ortognática (31), o que torna quase impossível realizar comparações dos resultados por meio de meta-análises (20). O presente trabalho torna-se inédito por avaliar as movimentações planejadas no planejamento virtual e comparar às movimentações encontradas na Mesa de Erickson por meio do Coeficiente de Correlação Intraclasses (CCI). Realizou-se também comparações quanto aos pontos de referência e quantidade de movimentação (3 e $6 \mathrm{~mm})$.

Os resultados demonstraram excelente concordância para os pontos de referência avaliados, independentemente da movimentação realizada. Constatou-se concordância quase perfeita entre os resultados previstos no planejamento virtual (realizado por meio do programa Dolphin Imaging $11.9^{\circledR}$ ) e as medidas encontradas na Mesa de Erickson.

Em muitos estudos clínicos, estabelece-se critérios de sucesso de $2 \mathrm{~mm}$ para diferenças lineares $(17,24,25,32)$, porém no presente estudo laboratorial, não foram encontradas diferenças estatisticamente significantes e a maior diferença linear encontrada foi $0,42 \mathrm{~mm}$ (vide Tabela 19). Este resultado demonstra a grande concordância entre os métodos de planejamento e a acurácia dos mesmos.

Por meio dos resultados encontrados, permite-se ainda reafirmar a alta acurácia do planejamento virtual, já descrita por inúmeros autores na literatura $(1,5,13,14,20,21,23)$ em estudos clínicos (comparativos entre pré-operatório e pós-operatório), assim como observar sua concordância com a cirurgia de modelos descrita por Erickson em 1989 (12).

O planejamento virtual 3D permite ganhos de tempo, diagnóstico detalhado, previsibilidade de interferências intraoperatórias e avaliação pós-operatória. Por outro lado, necessita de profissionais capacitados e adequada comunicação entre cirurgião e ortodontista para atingir o planejamento cirúrgico preciso (26). O planejamento tradicional por meio da cirurgia de modelos não difere neste aspecto e também necessita de capacitação e adequada comunicação entre ortodontistas e cirurgiões.

É possível atribuir os insucessos relatados na literatura à experiência de cada equipe, tanto em relação ao planejamento quanto ao ato cirúrgico, já que ambas ferramentas de planejamento em cirurgia ortognática demonstram-se precisas. A determinação da altura 
vertical da maxila é um parâmetro medido primariamente por medidas clínicas intraoperatórias, que podem influenciar de maneira decisiva a altura facial anterior. Por isso, muitos cirurgiões sugerem utilizar medidas clínicas para guiar a oclusão final e mentoplastia (24). Vale ressaltar que independentemente do tipo de planejamento, as limitações clínicas são as mesmas. Tais dificuldades não foram encontradas no presente trabalho, por tratar-se de um estudo laboratorial.

Outras dificuldades foram encontradas durante $\mathrm{o}$ estudo para realização do planejamento virtual, em virtude do treinamento necessário para compreensão do funcionamento do programa. É necessário treinamento intensivo e atenção a detalhes na marcação de pontos de referência no programa ("landmarks") que deveriam coincidir com os pontos marcados nos modelos de gesso montados em articulador semi-ajustável.

No planejamento cirúrgico virtual 3D cada observador pode posicionar os pontos de referência de maneira ligeiramente diferente e, para minimizar possíveis inconsistências na marcação dos pontos de referência ("landmarks"), autores sugerem que pontos imóveis na base do crânio (que não serão afetados pelo procedimento cirúrgico) podem servir como planos de referência internos. Outra dificuldade é que a depender do nível de precisão um ponto pode também ser uma superfície. Torna-se portanto, difícil definir um ponto de referência reprodutível em um modelo 3D. Um único observador é uma solução para minimizar a possível discrepância entre observadores.(25) O presente estudo, diferentemente de outros trabalhos da literatura $(2,5,11,25)$, teve apenas um único operador em todas as etapas executadas.

O planejamento tradicional na Mesa de Erickson, segundo alguns autores, tem severas limitações, pois é associado a radiografias bidimensionais e simulação cirúrgica em articulador semi-ajustável. Há um insuficiente controle do posicionamento maxilar em relação à base do crânio. Rotações anti-horárias do complexo maxilomandibular são difíceis de realizar e o posicionamento condilar adequado não é garantido.(2-4) Afirma-se ainda que erros podem ser introduzidos em cada uma das etapas que compõem a Cirurgia de Modelos.(5)

O presente trabalho, por outro lado, demonstra que, de acordo com os resultados obtidos, a obtenção de guias cirúrgicos em cirurgia ortognática por meio da Cirurgia de Modelos é semelhante ao planejamento cirúrgico virtual 3D. Apesar da complexidade de etapas e do maior tempo necessário segundo Wrzosek et. al. 2016 (11), o presente estudo não obteve diferenças estatisticamente significantes em relação à precisão do posicionamento maxilar.

Zinser et. al. 2013 afirmam que há claramente uma maior precisão do planejamento virtual quando comparado à técnica clássica.(2) $\mathrm{O}$ presente estudo discorda dos referidos 
autores, pois observou-se concordância quase perfeita entre os métodos quanto à obtenção dos guias cirúrgicos. Reconhece-se, por outro lado, as vantagens do planejamento virtual 3D em relação à técnica clássica no que se refere ao menor tempo gasto, melhor previsibilidade do resultado nos tecidos moles e maior previsibilidade quanto à necessidade de remoção de interferências ósseas no intraoperatório.

O planejamento cirúrgico virtual 3D traz inúmeras facilidades para o cirurgião, porém, cada etapa do seu protocolo deve ser executada com precisão, pois a acurácia de cada passo é construída na etapa anterior. (24) Da mesma forma, a Cirurgia de Modelos também necessita de cuidado e precisão na execução de suas etapas.

Outro detalhe importante observado no presente estudo, foi a necessidade de pequenos ajustes e desgastes realizados com brocas e peça de mão nos guias cirúrgicos obtidos pelo planejamento virtual 3D. Vale ressaltar que este tipo de obtenção dos guias cirúrgicos não exime o cirurgião de avaliá-los na arcada dentária dos pacientes antes do procedimento, e eventualmente, ajustá-los utilizando método semelhante à técnica clássica.

Outra fonte de erros no planejamento virtual 3D é a diferença entre a posição mandibular do paciente quando colocado em posição supina e posição ereta. A mandíbula tende a ser posicionada mais posteriormente quando o paciente encontra-se deitado, com a boca fechada em posição relaxada de oclusão em relação cêntrica. A mandíbula pode ser posicionada muito posteriormente (em virtude do relaxamento muscular e posicionamento supino do paciente anestesiado) e prejudicar todo o planejamento previamente realizado. Sugere-se que o cirurgião deve monitorar a todo momento a procedimento cirúrgico por meio das medidas clínicas para guiar a oclusão final e evitar que ocorra projeção abaixo do planejado.(24)

Outros autores afirmam que há uma tendência de projeção abaixo do planejado para os maxilares em cirurgia ortognática. Atribuem tal fato à dificuldades quanto ao posicionamento condilar durante o procedimento cirúrgico. Quando a maxila é manipulada, o segmento maxilar fica suscetível à mandíbula como referência para ajustar-se na nova posição. Para guiar a maxila, a mandíbula juntamente com o guia cirúrgico deve ser posicionada na direção pósterosuperior da fossa articular pelo cirurgião. Porém, não há nenhum ponto de referência anatômico ou memória muscular disponível para servir como guia e confirmar o posicionamento mandibular (25).

Corroborando com a literatura, minimizou-se possíveis erros posturais ocorridos durante a aquisição da imagem tomográfica por meio de um passo muito importante durante o planejamento virtual 3D: o posicionamento mandibular de acordo com os modelos escaneados 
em oclusão antes da realização da movimentação planejada da maxila. Este passo evita que ocorram divergências entre a oclusão do paciente em relação cêntrica e sua relação interoclusal durante a tomografia (geralmente realizada por um técnico em Radiologia e sem a supervisão do cirurgião que conduzirá o caso). Muitos cirurgiões também optam por utilizar guias em resina acrílica (JIGs) para controlar a oclusão do paciente durante a tomografia.

Na comparação com outros estudos, algumas diferenças significativas e importantes são encontradas. Por tratar-se de um estudo laboratorial, não sofreu influência da técnica cirúrgica e obteve-se como maior diferença entre os métodos de obtenção dos guias cirúrgicos o valor de 0,42mm. Outros estudos clínicos como o de De Riu et. al.2017 encontraram como maior erro o valor linear de 1,98mm.(24) Já Tran et. al. 2018 relataram diferenças lineares de até 1,46mm (26), Chin et. al. 2017 encontraram erro de até 12,57mm (25) e Zhang et.al. 2016 relataram maior diferença linear de 0,97mm.(3) Estes resultados evidenciam portanto, de maneira comparativa, a excelente concordância obtida no presente trabalho.

Também obteve alto nível de similaridade o estudo realizado por Centenero \& Hernández-Alfaro em 2012, que avaliou os resultados obtidos em 16 pacientes submetidos à cirurgia ortognática utilizando guias cirúrgicos convencionais e guias cirúrgicos impressos por meio do planejamento virtual 3D. Os autores também encontraram alto nível de concordância, classificando as diferenças menores que $1 \mathrm{~mm}$ como altamente semelhantes. Concluem que o planejamento virtual 3D é uma técnica válida e confiável. Os autores afirmaram ainda que na época as pequenas diferenças encontradas ocorreram pela dificuldade na avaliação das estruturas dentárias (não utilizou-se scanners intraorais) e pela variabilidade no comportamento dos tecidos moles (edema, acesso cirúrgico e tônus muscular).(17)

O presente trabalho torna-se portanto inovador, por utilizar o escaneamento de arcadas e não estar susceptível às interferências geradas pelo ato cirúrgico citadas anteriormente.

A etapa laboratorial para obtenção dos guias cirúrgicos analisada é de grande importância para alcançar resultados precisos em cirurgia ortognática. Não é possível, porém, por meio do presente trabalho, estabelecer um método padrão ("gold standard") para a referida etapa. Ambas as metodologias empregadas apresentaram resultados laboratoriais semelhantes, e assim, acredita-se que os insucessos relatados na literatura relacionam-se muito provavelmente à questões inerentes à técnica cirúrgica, anatomia e físiologia do pacientes e experiência do cirurgião. 


\section{CONCLUSÃO}

Por fim, de acordo com a metodologia empregada, conclui-se que a obtenção de guias cirúrgicos por meio do planejamento virtual $3 \mathrm{D}$ em cirurgia ortognática possui excelente concordância com a tradicional Mesa de Erickson (Cirurgia de Modelos), independentemente da quantidade de movimentação (3 ou $6 \mathrm{~mm}$ ) ou do ponto de referência avaliado. 


\section{REFERÊNCIAS ${ }^{*}$}

1. Farrell BB, Franco PB, Tucker MR. Virtual surgical planning in orthognathic surgery. Oral Maxillofac Surg Clin North Am. 2014;26(4):459-73.

2. Zinser MJ, Sailer HF, Ritter L, Braumann B, Maegele M, Zöller JE. A paradigm shift in orthognathic surgery? A comparison of navigation, computer-aided designed/computeraided manufactured splints, and "classic" intermaxillary splints to surgical transfer of virtual orthognathic planning. J Oral Maxillofac Surg. 2013;71(12):1-21.

3. Zhang N, Liu S, Hu Z, Hu J, Zhu S, Li Y. Accuracy of virtual surgical planning in twojaw orthognathic surgery: comparison of planned and actual results. Oral Surg Oral Med Oral Pathol Oral Radiol. 2016;122(2):143-51.

4. Shaheen E, Sun Y, Jacobs R, Politis C. Three-dimensional printed final occlusal splint for orthognathic surgery: design and validation. Int J Oral Maxillofac Surg. 2016;46(1):67-71.

5. Mazzoni S, Bianchi A, Schiariti G, Badiali G, Marchetti C. Computer-aided design and computer-aided manufacturing cutting guides and customized titanium plates are useful in upper maxilla waferless repositioning. J Oral Maxillofac Surg. 2015;73(4):701-7.

6. Kuehle R, Berger M, Saure D, Hoffmann J, Seeberger R. High oblique sagittal split osteotomy of the mandible: assessment of the positions of the mandibular condyles after orthognathic surgery based on cone-beam tomography. Br J Oral Maxillofac Surg. 2016;54(6):638-42.

7. Pietruski P, Majak M, Swiatek-Najwer E, Popek M, Szram D, Zuk M, et al. Accuracy of experimental mandibular osteotomy using the image-guided sagittal saw. Int J Oral Maxillofac Surg. 2016;45(6):793-800.

8. Meulstee J, Liebregts J, Xi T, Vos F, de Koning M, Bergé S, et al. A new 3D approach to evaluate facial profile changes following BSSO. J Cranio-Maxillofacial Surg. 2015 Dec;43(10):1994-9.

9. Liebregts J, Xi T, Timmermans M, de Koning M, Bergé S, Hoppenreijs T, et al. Accuracy of three-dimensional soft tissue simulation in bimaxillary osteotomies. J CranioMaxillofacial Surg. 2015 Apr;43(3):329-35.

10. Liebregts JHF, Timmermans M, De Koning MJJ, Bergé SJ, Maal TJJ. ThreeDimensional Facial Simulation in Bilateral Sagittal Split Osteotomy: A Validation Study

\footnotetext{
* De acordo com Estilo Vancouver.
} 
of 100 Patients. J Oral Maxillofac Surg. 2015;73(5):961-70.

11. Wrzosek MK, Peacock ZS, Laviv A, Goldwaser BR, Ortiz R, Resnick CM, et al. Comparison of time required for traditional versus virtual orthognathic surgery treatment planning. Int J Oral Maxillofac Surg. 2016;45(9):1065-9.

12. Erickson K. Analytic Model Surgey. J Oral Maxillofac Surg. 1989;47(8):30-1.

13. Hatamleh M, Turner C, Bhamrah G, Mack G, Osher J. Improved Virtual Planning for Bimaxillary Orthognathic Surgery. J Craniofac Surg. 2016;27(6):e568-73.

14. Hernández-Alfaro F, Guijarro-Martínez R. New protocol for three-dimensional surgical planning and $\mathrm{CAD} / \mathrm{CAM}$ splint generation in orthognathic surgery: An in vitro and in vivo study. Int J Oral Maxillofac Surg. 2013;42(12):1547-56.

15. Nilsson J, Thor A, Kamer L. Development of workflow for recording virtual bite in the planning of orthognathic operations. Br J Oral Maxillofac Surg. 2015 Apr;53(4):384-6.

16. Nilsson J, Richards RG, Thor A, Kamer L. Virtual bite registration using intraoral digital scanning, CT and CBCT: In vitro evaluation of a new method and its implication for orthognathic surgery. J Cranio-Maxillofacial Surg. 2016 Sep;44(9):1194-200.

17. Aboul-Hosn Centenero S, Hernández-Alfaro F. 3D planning in orthognathic surgery: $\mathrm{CAD} / \mathrm{CAM}$ surgical splints and prediction of the soft and hard tissues results - Our experience in 16 cases. J Cranio-Maxillofacial Surg. 2012;40(2):162-8.

18. Herford AS, Stringer DE, Tandon R. Mandibular surgery technologic and technical improvements. Oral Maxillofac Surg Clin North Am. 2014;26(4):487-521.

19. Swennen GRJ. Timing of three-dimensional virtual treatment planning of orthognathic surgery: A prospective single-surgeon evaluation on 350 consecutive cases. Oral Maxillofac Surg Clin North Am. 2014;26(4):475-85.

20. Stokbro K, Aagaard E, Torkov P, Bell RB, Thygesen T. Virtual planning in orthognathic surgery. Int J Oral Maxillofac Surg. 2014;43(8):957-65.

21. Hemelen G Van, Genechten M Van, Renier L, Desmedt M, Verbruggen E, Nadjmi N. Three-dimensional virtual planning in orthognathic surgery enhances the accuracy of soft tissue prediction. J Cranio-Maxillofacial Surg. 2015;43(6):918-25.

22. Borba AM, Haupt D, de Almeida Romualdo LT, da Silva ALF, da Graça NaclérioHomem M, Miloro M. How Many Oral and Maxillofacial Surgeons Does It Take to Perform Virtual Orthognathic Surgical Planning? J Oral Maxillofac Surg. 2016;74(9):1807-26.

23. Resnick CM, Inverso G, Wrzosek M, Padwa BL, Kaban LB, Peacock ZS. Is There a 
Difference in Cost Between Standard and Virtual Surgical Planning for Orthognathic Surgery? J Oral Maxillofac Surg. 2016;74(9):1827-33.

24. De Riu G, Virdis PI, Meloni SM, Lumbau A, Vaira LA. Accuracy of computer-assisted orthognathic surgery. J Cranio-Maxillofacial Surg. 2018;46(2):293-8.

25. Chin SJ, Wilde F, Neuhaus M, Schramm A, Gellrich NC, Rana M. Accuracy of virtual surgical planning of orthognathic surgery with aid of CAD/CAM fabricated surgical splint-A novel 3D analyzing algorithm. J Cranio-Maxillofacial Surg. 2017;45(12):1962-70.

26. Tran NH, Tantidhnazet S, Raocharernporn S, Kiattavornchareon S, Pairuchvej V, Wongsirichat N. Accuracy of Three-Dimensional Planning in Surgery-First Orthognathic Surgery: Planning Versus Outcome. J Clin Med Res. 2018;10(5):429-36.

27. SCHALL R. Estimation in generalized linear models with random effects. Biometrika. 1991;78(4):719-27.

28. Carrasco, JL; King, TS; Chinchilli V. The concordance correlation coefficient for repeated measures estimated by variance components. J Biopharm Stat. 2009;19:105.

29. Bland MJ e AGD. Comparing methods of measurement: why plotting difference against standard method is misleading. Lancet. 1995;346:1085-7.

30. R Core Team. R: A language and environment for statistical computing. R Foundation for Statistical Computing. Vienna, Austria; 2017.

31. Lin HH, Lo LJ. Three-dimensional computer-assisted surgical simulation and intraoperative navigation in orthognathic surgery: A literature review. J Formos Med Assoc. 2015;114(4):300-7.

32. Zinser MJ, Mischkowski RA, Sailer HF, Zöller JE. Computer-assisted orthognathic surgery: Feasibility study using multiple CAD/CAM surgical splints. Oral Surg Oral Med Oral Pathol Oral Radiol. 2012;113(5):673-87. 